Portland State University

PDXScholar

$1-1-2012$

\title{
The Influence of Parental Gender on the Type of Communication between Incarcerated Parents and Their Children
}

Sarah Renee Lazzari

Portland State University

Follow this and additional works at: https://pdxscholar.library.pdx.edu/open_access_etds

Part of the Criminology Commons

Let us know how access to this document benefits you.

Recommended Citation

Lazzari, Sarah Renee, "The Influence of Parental Gender on the Type of Communication between Incarcerated Parents and Their Children" (2012). Dissertations and Theses. Paper 805.

https://doi.org/10.15760/etd.805

This Thesis is brought to you for free and open access. It has been accepted for inclusion in Dissertations and Theses by an authorized administrator of PDXScholar. Please contact us if we can make this document more accessible: pdxscholar@pdx.edu. 
The Influence of Parental Gender on the Type of Communication between Incarcerated Parents and Their Children

$$
\text { by }
$$

Sarah Renee Lazzari

\begin{abstract}
A thesis submitted in partial fulfillment of the requirements for the degree of

Master of Science

in

Criminology and Criminal Justice
\end{abstract}

Thesis Committee:

Laura Hickman, Chair

Emily Salisbury

Brian Renauer

Portland State University

(C) 2012 


\begin{abstract}
The number of children in the United States with an incarcerated parent continues to rise. Currently, more than 1.7 million children have at least one incarcerated parent. In addition, research has found that children with criminally involved parents are at a higher risk of also becoming offenders (Glaze \& Maruschak, 2010). Research has shown that incarcerated parents’ abilities to maintain communication with their children may decrease negative behaviors while incarcerated and may decrease the negative effects of being removed from their families. The current study utilizes secondary data to explore the types of communication incarcerated parents use in order to stay connected with their children. The goal is to understand gendered differences regarding how incarcerated mothers versus incarcerated fathers choose to communicate with their children, and to understand which forms of communication (letter writing, face to face visits, and phone calls) are utilized most often by incarcerated parents to maintain and strengthen the bonds with their children. Logistic Regressions identified that incarcerated mothers are more likely to have at least one visit, phone call, and will utilize more forms of communication in a month's time, with their children. These findings both support and contradict previous studies. Implications of the findings and further suggestions are discussed.
\end{abstract}




\section{Dedication}

To all the mothers and fathers incarcerated throughout Oregon, I hope that I can shed some light onto the difficulties of maintaining strong family bonds during periods of incarceration. 


\section{Acknowledgements}

I would like to thank Dr. Mark Eddy and the Oregon Social Learning Center (OSLC) for allowing me to explore their incredibly rich data. Dr. Eddy, thank you for being a part of my educational process and brainstorming the formulation of my thesis. I'd also like to thank Alice Wheeler (OSLC) who was very gracious in fielding all of my questions about the data set. And thanks to Alice Holmes and the Project Home team who allowed me to intern at OSLC, which opened the opportunity to utilize the rich data collected by Dr. Mark Eddy.

Dr. Laura Hickman, thank you for being such a support and guide throughout this experience, and for always believing in my abilities. Where would I be without all of the incredible drawings that helped me to envision my thesis? I am so lucky to have you in my corner.

Dr. Emily Salisbury, thanks for always believing in me and for being a constant support of my educational process.

Dr. Brian Renauer, thank you for taking a chance on me, when I applied for the Masters in Criminology and Criminal Justice here at Portland State University.

To my classmates, Megan Glavin, Denise Austin, and Courtney Shrifter who so graciously read through my thesis, provided insight to help make my thesis even stronger, and helped with formatting of the analyses. I wish you all the best and know that each of you has an incredible journey ahead of you. 
To Dr. Hyeyoung Woo, I appreciate the time you took in providing feedback. Thank you for seeing my potential and for helping me through this process.

And finally, to my parents who have always supported my educational process. Thanks for being so incredible, and for always being my loudest cheerleaders! 


\section{Table of Contents}

$\begin{array}{lr}\text { Abstract } & \text { i } \\ \text { Dedication } & \text { ii }\end{array}$

Acknowledgements iii

List of Tables

$\begin{array}{ll}\text { Introduction and Review of the Literature } & 1\end{array}$

$\begin{array}{ll}\text { Communication in Oregon’s Prisons } & 12\end{array}$

$\begin{array}{ll}\text { The Present Study } & 14\end{array}$

$\begin{array}{ll}\text { Methods } & 17\end{array}$

$\begin{array}{ll}\text { Analysis } & 30\end{array}$

Results 32

$\begin{array}{ll}\text { Summary } & 46\end{array}$

$\begin{array}{ll}\text { Discussion } & 48\end{array}$

$\begin{array}{ll}\text { References } & 54\end{array}$

$\begin{array}{ll}\text { Appendix A: Regression Tables } & 61\end{array}$

$\begin{array}{ll}\text { Appendix B: Human Subjects Review } & 68\end{array}$ 


\section{List of Tables}

$\begin{array}{lll}\text { Table } 1 & \text { Incarcerated Parents’ Demographics } & 20\end{array}$

Table 2 Target Children’s Demographics $\quad 21$

Table 3 Original Race/Ethnicity Categories for Incarcerated Parents 25

Table $4 \quad$ Results of Chi-Square analysis of all dependent variables 34

Table5 Logistic Regression Results for Model 9 analyzing visits with the 37 Target Child

Table $6 \quad$ Logistic Regression Results for Model 9 analyzing phone calls with 38 the Target Child

Table $7 \quad$ Logistic Regression Results for Model 9 analyzing letters received 39 from the Target Child

Table 8 Logistic Regression Results for Model 9 analyzing letters sent to the 40 Target Child

Table 9 Logistic Regression Results for Model 9 analyzing letters being sent 42 and received

Table 10 Logistic Regression Results for Model 9 analyzing us of more than 43 one form of communication

Table 11 Logistic Regression Results for Model 9 analyzing use of all forms of 45 indirect communication

Table 12 Summary of all Hypotheses Results 


\section{Introduction and Review of the Literature}

Currently, there are over 1.7 million children in the United States whose parents are incarcerated (Glaze \& Maruschak, 2010). As of 2008, it was estimated that $75 \%$ of incarcerated women and 32\% of incarcerated men are parents (Bearse, 2008). The National Resource Center on Children and Families of the Incarcerated (2009) identified that 1 in 15 African American children and 1 in 42 Latino children (in comparison to 1 in 111 White children) have a parent in prison. Minority children, especially African American and Latino, are disproportionately affected by this growing phenomenon (Murray, 2005). These children often endure depression and decreased mental health, begin acting out in school and engaging in truancy, have higher rates of school dropout, have increased substance abuse, and are also five times more likely to become incarcerated (Bearse, 2008; Dallaire, Ciccone, \& Wilson, 2010; Harris \& Pettway, 2007; La Vigne, Davies, \& Brazzell, 2008; Loper \& Tuerk, 2006; Murray, Farrington, Sekol, \& Olsen, 2010; Oregon Department of Corrections, 2011; Tasca, Rodriguez, \& Zatz, 2011; Trice \& Brewster, 2004; Van de Rakt, Murray, \& Nieuwbeerta, 2012). Children of incarcerated parents may endure a loss similar to the death of a parent (Hairston, 2002; La Vigne, Davies, \& Brazzell, 2008). These children may also suffer from negative social stigma (Arditti, 2003; Arditti, Lambert-Shute, \& Joest, 2003; Hairston, 2002), shame, maltreatment by family members, and financial hardships (Hairston, 2002; La Vigne, Nesmith \& Ruhland, 2008; Davies, \& Brazzell, 2008). Children with incarcerated parents may also have a difficult time connecting with children whose parents are not 
incarcerated, which isolates them even further from their peers (Nesmith, \& Ruhland, 2008).These at-risk children, who may be shuffled between relatives' homes and foster care while their parents are incarcerated, are easily pushed aside and forgotten amidst the many problems facing society today (Eddy, Martinez, Schiffmnan, Newton, Olin, Leve, Foney, \& Shortt, 2008).

Many researchers assert communication between incarcerated parents and their children is critical if children are to move beyond the negative effects associated with separation from their parents (Cunningham, 2001; Dallaire, Ciccone, \& Wilson, 2010; Hairston, 2002; Harris \& Pettway, 2007; Loper \& Tuerk, 2006; Meek, 2007; Nickel, Garland, \& Kane, 2009; Poehlmann, Dallaire, Loper, \& Shear, 2010). Poehlmann, Dallaire, Loper, and Shear (2010) found that communication between incarcerated parents and their children has the ability to improve the children's development, increase the caregivers' mental health and physical health, and decreases incarcerated parents' levels of stress. Continued communication between incarcerated parents and their children also has been shown to increase the likelihood of a successful reentry for incarcerated parents, especially for incarcerated mothers (Arditti \& Few, 2008; Arditti \& Few, 2006; Poehlmann et al., 2010; Visher \& Travis, 2003). Visher and Travis (2003), through their examination of extant literature, found that any type of communication between incarcerated parents and their children had statistically significant effect sizes, and were found to be protective factors for the incarcerated parent and their children. The ability of the incarcerated parent and the child to maintain and create strong bonds may 
protect the child from some of the negative impacts of having a parent behind prison walls (Arditti, 2003; La Vigne, Davies, \& Brazzell, 2008). Unfortunately, there is a lack of consistency in the types of communication that incarcerated parents utilize in order to stay connected with their children (Poehlmann et al., 2010; Shlafer \& Poehlmann, 2010); and some parents choose not to contact their children to protect them from exposure to correctional facilities (Hairston, 2002).

Studies are beginning to examine how utilization of communication with children, during periods of parental incarceration, has varied gendered effects (Glaze \& Maruchak, 2009, Jiang \& Winfree; Loper, Carlson, Levitt, \& Scheffel, 2009; Nickel, Garland, \& Kane, 2009). Research continues to highlight the adverse effects of the "War on Drugs," particularly against low income mothers (Celinska \& Siegal, 2010), and how those parenting relationships are different for incarcerated mothers and fathers (Glaze \& Maruchak, 2009, Jiang \& Winfree; Loper, Carlson, Levitt, \& Scheffel, 2009). For both incarcerated mothers and fathers, the ability to communicate with their children has been shown to decrease incidences of self-reported prison violence (Loper et al., 2009). Maintaining communication with their children has been identified as one approach to reducing the likelihood that the incarcerated parents will become institutionalized or changed by negative adaptations that some inmates acquire during periods of incarceration, while also decreasing stress associated with the loss of their ability to traditionally parent their children (Jiang \& Winfree, 2006; Loper et al., 2009). 
According to Glaze and Maruschak (2010), by the end of 2007, the majority of incarcerated mothers (81\% for state prisoners and 75\% for federal inmates) throughout United States prisons lived with their children prior to incarceration versus only $36 \%$ of incarcerated fathers who lived with at least one of their children prior to incarceration. Similarly, studies suggest that the majority of children whose fathers are incarcerated lived with the biological mother (70\%-85\%), while only a small proportion of the children of incarcerated women lived with their biological fathers (20-29\%) (Glaze \& Maruschak, 2010; Johnson \& Waldfogel, 2002; Loper, Carlson, Levitt, \& Scheffel, 2009). The children of incarcerated mothers are also more likely to reside in foster care, when compared to the children of incarcerated fathers (Johnson \& Waldfogel, 2002; Loper et al, 2009).

Studies have also shown the emerging pattern that children of incarcerated mothers, when compared to children of incarcerated fathers, are at increased risk of becoming incarcerated (Dallaire, 2007; Luke, 2002). Dallaire (2007) found that adult children of incarcerated mothers are almost 3 times as likely, when compared to children of incarcerated fathers, to also become incarcerated. Trice and Brewster (2004), when examining the effects of maternal incarceration on school performance, found that children who maintained at least weekly communication with their incarcerated mothers performed the best in school and were the least likely of their peers, who had incarcerated mothers, to engage in criminal behaviors. 
Celinska and Siegal (2010) state that incarcerated mothers cope with the separation from their children by defending their roles as mothers and disassociating from their identities as prison inmates (Celinska \& Siegal, 2010). Therefore, incarcerated mothers have increased need for social interactions with their children, since they maintain the bonds with their children by communication efforts (Celinska \& Siegal, 2010; Jaing \& Winfree, 2006). Children are adversely affected when a parent goes to prison; but research argues that when a mother goes to prison, children may be impacted more significantly (Jiang \& Winfree, 2006; McGrath, 2012).

Incarcerated fathers tend to have less communication with their children prior to incarceration (Loper et al., 2009). Studies have identified that many incarcerated fathers were not a primary caretaker of their children, and had less contact with their children prior to becoming incarcerated (Glaze \& Maruschak, 2009; Harris \& Pettway, 2007; Loper et al., 2009). Loper and associates (2009) found that incarcerated fathers often had not cultivated their relationships with the children's caretakers, which made accessing the children very difficult once the fathers were incarcerated. Harris and Pettway (2007) argue that incarcerated fathers need specialized parenting programs to prevent their paternal roles from being minimized or completely abolished.

Maintaining the parent-child bond, by utilizing multiple forms of communication during incarceration, can help minimize the negative effects of losing a parent to imprisonment (Arditti, 2003; La Vigne, Davies, \& Brazzell, 2008). Communication during periods of incarceration can be very difficult, and unfortunately the children's 
caregivers may not diligently facilitate communication efforts between incarcerated parents and their children, especially for incarcerated fathers (Arditti, 2003; Arditti \& Few, 2008; Arditti, Lambert-Shute, \& Joest, 2003; Arditti, Smock, \& Parkman, 2005; Hairston, 2007; Harris \& Pettway, 2007; La Vigne, Davies, \& Brazzell, 2008; Shlafer \& Poehlmann, 2010). While communication has been shown to be a protective factor for incarcerated parents and their children, Arditti and Few (2006) suggest that some forms of communication, particularly face to face visits, may have negative effects on both the child and the incarcerated parent. Therefore, there is a need for more examination surrounding how incarcerated parents, mothers and fathers, communicate with their children. Communication during incarceration has been shown to predict the level of parental involvement with that child after the incarcerated parent is released (La Vigne, Naser, Brooks, \& Castro, 2005). For the most part, incarcerated parents are able to utilize three main forms of communication: face to face visits, phone calls, and letter writing. Therefore, each of these modes of communication is discussed in turn.

\section{Visits (Direct Communication)}

Interestingly, while visits have been shown to reduce the risk of recidivism for new felony convictions by $25 \%$ and technical parole/probation violations by $25 \%$, Duwe and Clark (2011) suggest that what needs to be examined is who is choosing to visit the inmate. Their study of incarcerated fathers found a small effect for visits from children, but there were larger reductions in recidivism when the inmate was visited by their own 
fathers, siblings, in-laws, and clergy. Duwe and Clark (2011) did not include incarcerated mothers in their study, which would have made for an interesting comparison.

Alternatively, the nature of the visiting room may negate the potential positive effects of an in person visit. Pollock (2002) highlighted the fact that visiting rooms in male institutions may look different than the visiting rooms in female institutions. Male visiting rooms are filled with wives and girlfriends, while female visiting rooms are often filled with nuclear and extended family members, not significant others. Many visiting rooms are loud, the parent may be behind glass, or there may be nothing in the visiting room to occupy young children (e.g., toys, puzzles, books, drawing materials, etc.). Other forms of communication allow the parent more control in what they communicate and how they communicate with their child. A parent may be better able to show stronger commitment to the child and feel more confident in their parenting abilities through utilizing other forms of contact, such as letter writing and phone calls (Poehlmann et al. 2010). The visits may be too short to allow time for meaningful emotional connections and to address pertinent issues. In addition, family members may not able to visit frequently (Arditti \& Few, 2006).

Celinska and Siegal (2010) found that $41 \%$ of incarcerated mothers in prison never received a visit from their children, while 75\% of incarcerated mothers in jails never received a visit from their children. Female inmates are much less likely to receive visits than are their male counterparts (Arditti \& Few, 2006; Gray, Mays, \& Stohr, 1995). Yet Loper and associates (2009) did not find statistically significant gendered differences 
in the amount of visits. But many studies consistently identify that visits remain infrequent for both mothers and fathers (Glaze \& Maruschak, 2010; Jiang \& Winfree, 2006; Johnson \& Waldfogel, 2002; La Vigne et al., 2005; Loper et al., 2009; Nesmith, \& Ruhland, 2008; Shlafer \& Poehlmann, 2010). Visits have also been shown to increase the incarcerated parents' level of stress because they worry about how their children will be affected and the financial burden placed on the caregiver (Hairston, 2007; Loper et al., 2009; Loper et al., 2005). Children may even express that they do not feel safe inside the prison walls during the visit (Nesmith \& Ruhland, 2008). Physical visits may remind the incarcerated parents of all that they are unable to be a part of in their children's lives, and in some cases increase negative behaviors in the institution, while the parent is incarcerated (Jiang \& Winfree, 2006; La Vigne, Davies, \& Brazzell, 2008; Loper et al., 2009).

Celinska and Siegal (2010) found that visits can be very difficult emotionally, and that phone calls and letters [also referred to as remote (Arditti \& Few, 2006) or indirect (Loper et al., 2009) forms of communication] are utilized most often by incarcerated parents. Visits have also been shown to increase children's troubled behaviors and may enforce an insecure attachment between the child and the incarcerated parent (Dallaire, Ciccone, \& Wilson, 2010; Poehlmann et al., 2010). Visiting rooms can be loud and uncomfortable, the family members may be treated disrespectfully by correctional officers, and incarcerated parents may find the continued hassles of institutions' visiting rules not worth the effort of a visit (Arditti, 2003; Arditti \& Few, 2006; Arditti, Lambert- 
Shute, \& Joest, 2003; Loper et al., 2009). Loper and associates (2009) found that while incarcerated parents may not always have monthly visits with their children, the majority of incarcerated parents have at least one indirect contact with their children each month.

Children of incarcerated parents may also express reservations about visiting their parents behind prison walls. If a child expresses concerns about the face-to-face visit, then communication should begin through phone calls and letter writing (Poehlmann, Dallaire, \& Shear, 2010; Shlafer \& Pohelmann, 2010). Remote forms of contact may be more effective in maintaining strong bonds with children. Jiang and Winfree (2006) found a negative relationship between the amount of rule infractions and phone calls and letter writing, while a positive relationship was found between the number of visits and the amount of rule violations. Jiang and Winfree (2006) also tested the forms of communication for gendered differences, and no statistically significant gender differences were found. The negative relationship between phone calls and the number of rule violations was the only statistically significant communication variable, and it was statistically significant for both genders (Jiang \& Winfree, 2006). The researchers were unable to address why certain communication variables were significant in reducing the amount of rule violations while others were not, and suggested further examination regarding the forms of communication and their influences on the incarcerated parents.

\section{Phone Calls and Letter Writing (Indirect/Remote Forms of Communication)}

Unfortunately, phone calls can be very expensive and therefore taxing on inmates’ stress levels and caregivers’ finances (La Vigne, Davies, \& Brazzell, 2008), and the 
infrequent phone calls do not allow strong relationships to be developed (Gray, Mays, \& Stohr, 1995). Caretakers may spend upwards of $\$ 85$ a month to have a weekly phone call with the children’s incarcerated parent (Grinstead, Faigeles, Bancroft, \& Zack, 2001).

Communication through letter writing has been shown to decrease children's anxiety about communicating with their incarcerated parent. A letter also allows the child and parent to thoroughly express how they are feeling, while providing a tangible reminder and keepsake from their loved one (Dallaire, Wilson, \& Ciccone, 2010). The cost of letter writing is minimal, which encourages more frequent communication without the stress of burdening the caregivers with high costs (Arditti \& Few, 2006; Poehlmann et al., 2008; Tuerk \& Loper, 2006).

Visiting a prison can be a frightening experience for children, and indirect forms of communication allow for a less intimidating way to stay connected with the incarcerated parent, especially if there was minimal contact prior to the parent being incarcerated (Jaing, \& Winfree, 2006; Poehlmann et al., 2010; Schlafer \& Poehlamnn, 2010; Loper et al., 2009). Indirect forms of communication may allow for the bond between the incarcerated parent and the child to form, while the parental relationship builds (Jiang \& Winfree, 2006). One complication of communication through letter writing is that the process of mailing a letter is slow and further impacted by reviews of inmate mail (Duwe \& Clark, 2011). Interestingly, there has not been much attention paid to literacy, and how an incarcerated parent's level of literacy affects their decision to send letters to their children. A future study should examine whether literacy affects an 
incarcerated parent's use of letter writing, and which incarcerated parents are communicating with their children through letter writing. 


\section{Communication in Oregon's Prisons}

Oregon's Administrative Rules (OARs), regarding the form of communications available to inmates and their loved ones are accessible from Oregon Department of Correction's (ODOC) website. Each form of communication is described below.

Phone calls (http://www.oregon.gov/DOC/GENSVC/faq-its.shtml) are made through Value Added Communications Inmate Telephone Service (VAC). VAC provides three types of phone services to inmates and their loved ones: advance pay, collect, and debit. Advance pay is an account set up through VAC that acts like a debit account. The loved ones are responsible for setting up this account. Collect calls are like traditional collect calls, where the charges are added to the loved one's phone bills. Finally, the debit account is set up by the inmate, and the money is taken from the inmate's account. Each facility within ODOC has different periods of times when inmates are allowed to call their loved ones. Most of the facilities have detailed information for when the calls can occur and the length of the calls. The call length varies between 20-30 minutes. There are also varied levels of access to phones based upon the inmate's security level.

Visits (http://arcweb.sos.state.or.us/pages/rules/oars_200/oar_291/291_127.html) are allowed once ODOC has received and approved the visitation application form for all visitors aged fifteen and older. Any child, thirteen or under, does not count as one of twenty individuals allowed on an inmate’s approved visiting list. Children under the age of eighteen must be accompanied by an adult during any visit. An inmate is allowed one visit per visiting day, unless previously established by an institution’s superintendent. An 
inmate who is subject to basic visitations can have eight visits per month. During basic visits, no more than two visitors and a minor child, under the age of three, can visit the inmate. The length of visits and the days that visits are allowed vary by institution.

\section{Letters}

(http://arcweb.sos.state.or.us/pages/rules/oars_200/oar_291/291_131.html) are reviewed by ODOC mailroom staff. All correspondence is examined, unless the correspondence is legal information, or there has been an exception granted by the institution. Pictures of the inmate's children can be sent to the incarcerated parent, but they cannot be a Polaroid; there are chemicals on the Polaroid that could potentially be used for other purposes. All letters sent from inmates to their children and other loved ones are also subject to institutional review, as they leave the facility. 


\section{The Present Study}

The research highlights patterns and contradictions about the type of communication that incarcerated mothers and incarcerated fathers utilize to maintain and build ties with their children. There needs to be further examination of the differences between the forms of communication utilized by incarcerated mothers versus incarcerated fathers. Many studies examine incarcerated fathers or incarcerated mothers but do not analyze incarcerated mother and incarcerated fathers concurrently. The purpose of this study is to address the gap in literature examining the differences between the forms of communication utilized by incarcerated mothers versus incarcerated fathers. This study will analyze whether incarcerated mothers versus incarcerated fathers were more likely to experience at least one visit, phone call, and/or letter received or letter sent to an identified target child. This study will also examine whether variations appear in gendered differences in accessing direct (visits) versus indirect (phone calls and letters) forms of communication.

Based on the review of the literature, I hypothesize that incarcerated mothers will utilize more forms of communication with their children because they are trying to maintain their parental roles. The majority of incarcerated mothers have been identified as the primary caretaker prior to incarceration, and communication can be utilized to maintain those bonds.

Incarcerated fathers are expected to utilize visits with their children more than incarcerated mothers, since there is only one Oregon female prison. But previous studies 
suggest conflicting patterns. Therefore, a competing hypothesis emerges: incarcerated mothers are more likely to receive at least one visit during the past month with their children.

There is also an expectation that incarcerated mothers will utilize indirect forms of communication (phone calls and letter writing), especially since there is only one female prison in the state of Oregon and their children may not be able to visit as frequently as the children of incarcerated fathers. But, again, there is a competing hypothesis: fathers utilize more indirect forms of communication (phone calls and letter writing) in order to build a relationship with their children, since research states that the majority of incarcerated fathers were not a primary caretaker of their children prior to incarceration. Children of incarcerated fathers may not be initially comfortable with visiting their father, who may not have been a primary parental influence in their lives. Indirect communication allows the incarcerated father and his children to build a relationship.

Finally, it is hypothesized that when phone calls and letter writing are analyzed separately, the expectation is that incarcerated mothers will utilize these forms of communication more than incarcerated fathers, since the literature identifies that the majority of mothers were primary caretakers prior to incarceration. This means that relationships between incarcerated mothers and their children may have already been formed, and continued communication attempts allow them to maintain their relationships. Similarly, since relationships may already be established between 
incarcerated mothers and their children, the expectation is that incarcerated mothers are more likely to receive a letter from their children, when compared to incarcerated fathers. When combined, it is expected that incarcerated mothers are more likely to have both sent a letter to their children and received a letter from their children. 


\section{Methods}

\section{Data Source}

In 2001, Oregon's legislature tasked the Children of Incarcerated Parents Project (CIP) with evaluating the current state and future direction of how parenting relationships are affected by Oregon's criminal justice system. The data being used for this study comes from a larger study (Parent Child Study), conducted by the Oregon Social Learning Center (OSLC), in conjunction with ODOC and the CIP. The larger study was an examination of the effects resulting from the Parenting Inside Out (PIO) Curriculum for Oregon prisons, that OSLC had been tasked to create. Initially, over 1400 inmates throughout Oregon were interested in being a part of the study. Inmates learned about the study through inmate newspapers, information placed throughout institutions, special announcements during regularly scheduled inmate club meetings, and recruitment meetings (Poehlmann \& Eddy, 2012). OSLC planned to conduct the study in three male facilities and the only female facility, and utilized incarcerated parents housed in minimum and medium security facilities. The four facilities chosen were in the Willamette Valley area of Oregon, which is a highly populated area (US Census Bureau, 2010). OSLC was interested in conducting the study in Oregon prisons that were known as institutions which released the majority of inmates back into the community. If participants were not located within the four facilities, they could request a transfer. The final sample includes 359 incarcerated mothers $(\mathrm{N}=198)$ and fathers $(\mathrm{N}=161)$ located throughout all fourteen of Oregon's prisons. The goal of the Parent Child Study was to 
assess how the Parenting Inside Out curriculum affected incarcerated parents and their children.

To be eligible for the study, the participants had to have at least one minor child (desired age range was 5-11); were able to have contact with their child; were either in a parenting role with the child or expected to have a parenting role for the child in the future; were able to give contact information for the caregiver of their child; had not committed a sex crime or crime against a child; had less than nine months remaining on their sentence; and if not currently housed in a releasing institution, ODOC would agree to transfer the incarcerated parent to one of the study facilities (Poehlmann \& Eddy, 2012).

While the OSLC study randomly assigned participants to a treatment and control group, and collected interview data at multiple time points, the current study utilizes the baseline data and includes both the treatment and control group participants. The baseline data was collected through face to face interviews with inmates and OSLC researchers, prior to the beginning of the PIO courses. OSLC piloted the program with incarcerated men and women throughout Oregon prisons, beginning in 2003. Multiple time points of data were collected in the longitudinal study including baseline (which were interviews conducted prior to the beginning of the parenting program), during the parenting intervention, at the completion of the parenting intervention, and after the parent was released from prison. The respondents were randomly assigned to a control or treatment group. A unique aspect of the study was that the incarcerated parents were asked to 
identify one specific target child. The incarcerated parent then answered questions specifically about that one child; many studies combine all the children, and don't focus on one specific child. A unique componenet of OSLC's study was that information was also gathered from a caregiver of the specific target child and the target child. But for the present study, information gathered from the incarcerated parent's point of view will be utilized.

\section{Sample}

The baseline data contained 359 inmate parent respondents. The average age of the respondents, at the time of the baseline, was 32 years. Inmate mothers (55\%) were oversampled, as were inmates of color (40\%). Thirty-seven percent of the sample had less than a high school diploma, 31\% had a high school diploma or a GED, and 32\% had at least some college. The respondents had an average of three children. Incarcerated mothers $(M=3.34, S D=2.31)$ had a slightly lower, but not statistically significant different average number of children, when compared to the incarcerated fathers $(M=$ $3.44, S D=2.43)$. The majority of the incarcerated parents (56\%) did not live with their children prior to incarceration. Approximately $44 \%$ of mothers and $43 \%$ of fathers lived with at least one of their children prior to incarceration. The sample for this study is different from previous studies, which identified that the majority of incarcerated mothers, upwards of 70\%, were living with their children prior to incarceration (Glaze \& Maruschak, 2009; Loper et al., 2009). This may be due to the way in which the participant recruitment occurred. Incarcerated parents had to initiate their willingness to 
participate in the study, and this may have been influenced by their desire to strengthen the relationship with their children (Poehlmann \& Eddy, 2012).

Table 1

Incarcerated Parents’ Demographics

\begin{tabular}{|c|c|c|c|c|c|c|}
\hline \multirow[b]{2}{*}{ Variables } & \multicolumn{2}{|c|}{ Males } & \multicolumn{2}{|c|}{ Females } & \multirow[b]{2}{*}{ Totals } & \multirow[b]{2}{*}{$\%$} \\
\hline & $N$ & $\%$ & $N$ & $\%$ & & \\
\hline \multicolumn{7}{|l|}{ Minority Status } \\
\hline White & 94 & 58.4 & 120 & 60.6 & 214 & 59.6 \\
\hline Other & 67 & 41.6 & 78 & 39.4 & 145 & 40.4 \\
\hline Totals & 161 & & 198 & & 359 & \\
\hline \multicolumn{7}{|l|}{ Education } \\
\hline Less than a HS Diploma/GED & 54 & 33.5 & 80 & 40.4 & 134 & 37.3 \\
\hline HS Diploma/GED & 53 & 32.9 & 58 & 29.3 & 111 & 30.9 \\
\hline At Least Some College & 54 & 33.5 & 60 & 30.3 & 114 & 31.8 \\
\hline Totals & 161 & & 198 & & 359 & 0 \\
\hline \multicolumn{7}{|l|}{ Number of children } \\
\hline One Child & 29 & 18.7 & 34 & 17.5 & 63 & 18.1 \\
\hline Two Children & 39 & 25.2 & 54 & 27.8 & 93 & 26.6 \\
\hline Three Children & 23 & 14.8 & 35 & 18.0 & 58 & 16.6 \\
\hline Four Children & 25 & 16.1 & 25 & 12.9 & 50 & 14.3 \\
\hline Five Children & 19 & 12.3 & 17 & 8.8 & 36 & 10.3 \\
\hline More than five Children & 20 & 12.9 & 29 & 14.9 & 49 & 14.0 \\
\hline Totals & 155 & & 194 & & 349 & \\
\hline \multicolumn{7}{|c|}{$\begin{array}{l}\text { Lived with at least one of their children } \\
\text { before incarceration }\end{array}$} \\
\hline No & 91 & 57.2 & 110 & 55.6 & 201 & 56.3 \\
\hline Yes & 68 & 42.8 & 88 & 44.4 & 156 & 43.7 \\
\hline Totals & 159 & & 198 & & 357 & \\
\hline \multicolumn{7}{|l|}{ Substance Abuse } \\
\hline No & 24 & 14.9 & 15 & 7.6 & 39 & 10.9 \\
\hline Yes & 137 & 85.1 & 183 & 92.4 & 320 & 89.1 \\
\hline Totals & 161 & & 198 & & 359 & \\
\hline
\end{tabular}

${ }^{1} \mathrm{TC}=$ Target Child

While many inmates have multiple children, the respondents were asked to identify one child. The identified child, also referred to as the target child, served as the subject for how the incarcerated parent answered interview questions. The desired age range for this child was between the ages of 5 and 12. This age range was determined 
based upon previous studies that were similar to OSLC’s Parent Child Study (J.M. Eddy, personal communication, May 1, 2012). Eighty-four percent of the target children were between the ages of 5-12, while approximately sixteen percent of the target children were either older or younger than the desired age range. In order to maintain a large enough sample size, OSLC researchers made exceptions regarding the desired age range and aimed to maintain the average age of the target children in the middle of the desired age range. The average age for the target children was 8 years old. The youngest target child was almost 1 year old and the oldest was almost 15 years old.

Table 2

Target Children’s Demographics

\begin{tabular}{|c|c|c|c|c|c|c|}
\hline \multirow[b]{2}{*}{ Variables } & \multicolumn{2}{|c|}{ Males } & \multicolumn{2}{|c|}{ Females } & \multirow[b]{2}{*}{ Totals } & \multirow[b]{2}{*}{$\%$} \\
\hline & $\mathrm{N}$ & $\%$ & $\mathrm{~N}$ & $\%$ & & \\
\hline \multicolumn{7}{|l|}{ Sex } \\
\hline Male & 170 & 47.4 & & & & \\
\hline Female & & & 188 & 52.4 & & \\
\hline Totals & & & & & 358 & 99.7 \\
\hline Missing & & & & & 1 & .3 \\
\hline \multicolumn{7}{|c|}{ Minority Status } \\
\hline White & 89 & 55.6 & 95 & 57.2 & 184 & 56.4 \\
\hline Other & 71 & 44.4 & 71 & 42.8 & 142 & 43.6 \\
\hline Totals & 160 & & 166 & & 326 & \\
\hline Missing & & & & & 33 & \\
\hline \multicolumn{7}{|l|}{ Age } \\
\hline Under 5 & 22 & 12.9 & 24 & 12.8 & 46 & 12.8 \\
\hline $5-9$ & 102 & 60.0 & 97 & 51.6 & 199 & 55.6 \\
\hline $10-15$ & 46 & 27.1 & 67 & 35.6 & 113 & 31.6 \\
\hline Totals & 170 & & 188 & & 358 & \\
\hline \multicolumn{7}{|c|}{$\begin{array}{l}\text { Within the desired age } \\
\text { range (5-12) }\end{array}$} \\
\hline No & 29 & 17.1 & 27 & 14.4 & 56 & 15.6 \\
\hline Yes & 141 & 82.9 & 161 & 85.6 & 302 & 84.4 \\
\hline
\end{tabular}




\section{Dependent Variables}

The number of visits, phone calls, letters sent, and letters received were original variables collected during OSLC’s baseline interviews. The incarcerated parents were asked to self-report the total number of such contacts with the target child over the previous month. For purposes of this study, communication was assessed utilizing dichotomous variables. First, I examined whether communication of various sorts happened at all over the previous one month period. Then variables were computed in order to assess whether more than one form of communication was utilized, and whether all three forms of indirect communication (letters sent, letters received, and phone calls) were being used by incarcerated mothers and fathers. In the OSLC study, inmate parents were asked whether and how frequently they had different forms of communication with the target child over a one month period.

In the present study, I am assessing the presence or absence of each form of communication, not its frequency. Future studies should assess longer periods of communication in order to analyze differences in the frequency of communication between incarcerated parents and their children.

For the present study, dichotomous dependent variables indicating whether a specific form of contact occurred $(=1)$ or did not occur $(=0)$ over the previous one month period, were all coded in the same fashion. Specifically, I will examine the following seven dependent variables: visits, phone calls, letters received from the target child, letters sent to the target child, whether letters were both sent and received, whether 
the parent participated in more than one form of communication, and whether all forms of indirect communication (phone calls, letters received from the target child, and letters received from the target child) were utilized. I acknowledge that the incarcerated parent has control only over one form of communication: sending letters to the target child. Visits require a caretaker to bring the target child to the facility; phone calls require someone to accept the collect call or to answer the phone; and letters received by the incarcerated parent require the target child initiating the contact. The present study is not analyzing who is responsible or whether the incarcerated parent is unable to initiate specific forms of communication, but rather is concerned with acknowledging whether the communication occurred.

\section{Independent Variable}

The independent variable of interest is the sex of the incarcerated parent (Males = 0, Females $=1)$.

\section{Control Variables}

I will also be utilizing multiple control variables: minority status of the incarcerated parent, education level of the incarcerated parent, the number of biological and non-biological children that the incarcerated parent has, whether the incarcerated parent lived with at least one of their children prior to incarceration, the age of the target child, whether the incarcerated parent had an issue with substance abuse, the length of time they had been incarcerated up to the baseline data collection, and the total length of 
sentence. Control variables were chosen based upon previous studies which utilized similar analyses.

The original study had categorized race/ethnicity into nine categories (See Table 3). Since there were no hypotheses regarding differences within minority groups in communication types, I want to account simply for variation related to whites versus minority groups. There may be cultural differences which may directly influence the types of communication utilized by parents. While controlling for minority status, I am able to account for the presence of possible cultural variations. The state of Oregon, where the data was collected, is not racially diverse and has a larger White (83.6\%) population than the overall White population in the United States (72.4\%) (U.S. Census Bureau, 2012). Therefore, the results may not be generalizable to other states. I originally recoded the race variable into multiple categories, but Whites account for approximately $60 \%$ of the sample. As a result, based on the distribution of the data, I recoded the variable into a dichotomous variable: (0) Other and (1) White. See Table 1 for new Minority Status information. 
Table 3

Original Race/Ethnicity Categories for Incarcerated Parents

\begin{tabular}{lcccccr}
\hline & \multicolumn{7}{c}{ Males } & \multicolumn{2}{c}{ Females } & \\
\cline { 2 - 5 } Race/Ethnicity & $N$ & $\%$ & $N$ & $\%$ & Totals & $\%$ \\
\cline { 2 - 4 }$\quad$ White & 94 & 58.4 & 120 & 60.6 & 214 & 59.6 \\
Black-African American & 24 & 14.9 & 21 & 10.6 & 45 & 12.5 \\
Black-Caribbean Island & 1 & .6 & 0 & 0 & 1 & .3 \\
Asian-Pacific Islander & 1 & .6 & 0 & 0 & 1 & .3 \\
Native & 13 & 8.1 & 15 & 7.6 & 28 & 7.8 \\
American/Aleutian/Eskimo & & & & & & 7.5 \\
Hispanic/Latino-Mexican & 10 & 6.2 & 17 & 8.6 & 27 & .3 \\
Hispanic/Latino-Puerto & 0 & 0 & 1 & .5 & 1 & 10.6 \\
Rican & 18 & 11.2 & 20 & 10.1 & 38 & 1.1 \\
Multiracial & 0 & 0 & 4 & 2 & 4 & 100 \\
Other & 161 & 100 & 198 & 100 & 359 & \\
Total & & & & & & \\
\hline
\end{tabular}

Incarcerated parents were asked about biological and non-biological children in separate questions. For the present study, these two variables were combined to create the total number of children for which the incarcerated parent claimed responsibility. While there was not a significant difference in the total number of children between incarcerated mothers $(M=3.12, S D=1.67)$ and incarcerated fathers $(M=3.17, S D=1.67, t(347)=.244, p>.05)$, the number of children ranged from one child to sixteen children. I wanted to control for this variation, and did not want the analysis to be effected by outliers. The target child was not the biological child of all the incarcerated parents. Thirteen percent of incarcerated fathers and almost 7\% of incarcerated mothers were not the biological parent of the target child. Therefore, I did not want to exclude these cases simply because they were not the biological parent of the 
target child. In all cases, these were children for which the incarcerated parent claimed some parental responsibility, or expected to have parental responsibility for the target child in the future (Poehlmann \& Eddy, 2012).

When interviewers asked whether the incarcerated parent lived with one or more of their children prior to incarceration, the incarcerated parents were not asked specifically about the target child. In a subsequent data collection, the incarcerated parents were asked about the specific target child. Alas, the incarcerated parent may have lived with a child, but they might not have lived with the target child. Whether the target child lived with the incarcerated parent prior to incarceration may have huge effects on the communication with the incarcerated parent. If the target child had not lived with the incarcerated parent, the target child may not be as bonded; and therefore, as cited in the literature, may not be as comfortable visiting the incarcerated parent (Jaing, \& Winfree, 2006; Poehlmann et al., 2010; Schlafer \& Poehlamnn, 2010; Loper et al., 2009). On the other hand, if the target child lived with the incarcerated parent prior to incarceration, there may be a stronger bond and a stronger desire for more communication with the incarcerated parent. Therefore, the results of the analysis may not be specific to the identified target child, but it remains an important component in establishing how the parent-child relationship effects utilizing certain forms of communication.

Substance abuse was captured as a dichotomous (0) no/ (1) yes question, and the present study did not assess the history of the substance abuse or the type of substance that was abused. The incarcerated parents were simply asked if they had ever experienced 
drug or alcohol abuse or addiction. Substance abuse, prior to incarceration, may affect the strength of the parent-child relationship. Jiang and Winfree (2006) utilized a similar control variable in their analysis and claimed that incarcerated parents who had engaged in drug/alcohol use had a harder time adjusting to prison life, and may have a harder time adjusting to institutional rules and maintaining ties with their families.

In the present analysis, the length of prison time already served and the total sentence length remained as continuous variables. Studies have suggested that inmates who have served longer lengths of time and have longer sentences are more likely to find a routine that works for them, in terms of communicating with their children (Jiang \& Winfree, 2006; Loper et al., 2009). They become used to the prison environment and have had time to establish a communication pattern with their families. An independent samples t-test was conducted to compare the length of time already served and the total sentence length for incarcerated mothers and fathers. There was a significant difference in the length of time already served for incarcerated mothers $(M=.92, S D=1.19)$ and incarcerated fathers $(M=1.70, S D=1.87 ; t(259)=4.59, p=.000)$. On average, incarcerated mothers had already served less than a year, while the incarcerated fathers had already served almost two years. For the entire sample, the range of time already served was less than one month to just over 10 years. There was also a significant difference in the sentence lengths for incarcerated mothers $(M=1.47, S D=1.22)$ and fathers $(M=2.22, S D=1.90 ; t(262)=4.35, p=.000)$. Incarcerated mothers had an average of almost one and a half years, while the incarcerated fathers averaged slightly 
over 2 years. For the entire sample, the total sentence length ranged between five months and almost 12 years. The presence of the significant differences was important to control for in the analyses.

A limitation of the original study design, which may affect this study, is that only one child could be identified as the subject of responses. The selection of the target child was restricted to a desired age range (5-12 years old). It could be that the incarcerated parent had a more significant relationship with another child outside of this age window. Therefore, the level of communication with the identified target child may not represent the level of communication with all the incarcerated parent's children. Similarly, all of the communication variables ask the incarcerated parent to identify how many of each type of communication they had with the target child during the past month. There were no questions asked which explored the content or quality of those communications. Moreover, available data does not capture whether the incarcerated parent only addressed the target child during a given communication attempt, or if the communication attempt was addressed with multiple children. However, interviews following the baseline do address other relational dynamics including their relationship with the target child's caretaker/s, how the target child is coping, and the effects of other relationships that the incarcerated parent has with other loved ones. The original study by OSLC is groundbreaking, and has continued importance in understanding the communication attempts between incarcerated parents and their children. 
Another limitation is that the present study did not examine the relationship between the incarcerated parent and the target child's caregiver, income level of the caregiver, or distance that the caregiver lived from the facility where the parent was incarcerated. The larger study, conducted by OSLC, did address some of these issues. Another line of research should examine the influence of religion and religious conversions that occur after longer periods of incarceration. These variables need to be examined in a future study, in order to account for relationship dynamics which may directly influence the likelihood of communication efforts between incarcerated parents and their children. Incarceration is a very complex situation, and there are a multitude of variables which may affect the likelihood of continued communication between the incarcerated parent and their children. 


\section{Analyses}

Chi-Square tests for independence were conducted to compare the proportion of incarcerated mothers versus fathers and their participation in each form of communication (see Table 4). This test highlights whether there are statistically significant differences in the proportions of incarcerated mothers and incarcerated fathers choosing to participate in different forms of communication.

Logistic regression analyses were then conducted to test whether any of the seven dependent variables were significantly influenced by parent sex, while controlling for the following variables: minority status, education, number of children, whether the parent had lived with the child prior to incarceration, substance abuse, length of incarceration at the time of the baseline, and total sentence length. In all analyses, parent sex was coded as male $=0$, female $=1$.

The independent variable, incarcerated parent's sex, was assessed in all of the regression models, and then control variables were individually added into each subsequent model. The subsequent models show whether the independent variable continues to play a statistically significant role in the utilization of each form of communication. There are a total of nine regression models for each dependent variable (see Appendix A).

The first analysis includes only the incarcerated parents’ sex, with male $=0$ and female $=1$ (Model 1). Minority Status, with Other=0 and White=1, is then added in Model 2. Education is added in Model 3, with less than a HS Diploma=1, HS 
Diploma/GED=2, and at least some College=3. Model 4 includes the incarcerated parent's total number of children, and is left as a continuous variable that includes both biological and non-biological children. Whether the incarcerated parent lived with at least one of their children prior to incarceration is added in Model 5, with no=0 and yes $=1$. The age of the target child is included in model 6, and is also left as a continuous variable. Self-reported substance abuse of the incarcerated parent is included in Model 7, with no $=0$ and yes $=1$. The length of incarceration already served by the incarcerated parent at the time of the baseline interview is included in Model 8 as a continuous variable. The final model, Model 9, adds the total sentence length given to the incarcerated parent at their trial.

For purposes of the present study, Model 9 of the regression models will be interpreted for each dependent variable. This will allow for a sense of how large a role the sex of the incarcerated parent plays when other factors are taken into consideration. Results for each of the communication dependent variables will be discussed in turn. 


\section{Results}

In this section, I will first explain some of the variation in the types of communication between incarcerated mothers and fathers. Table 4 is then presented, which shows the results from Chi-Squares, examining whether statistically significant differences appear in the proportions between the forms of communication utilized by incarcerated mothers versus incarcerated fathers. The results from the logistic regressions, for each dependent variable, are then presented. Tables were created to highlight the results from the final models. The full regression models, including all nine models, are displayed in Appendix A.

\section{Chi-Squares}

In every category of communication, women were more likely than men to have utilized the method to communicate with the target child. In the simple comparison of percentages, a higher proportion of women had a visit from the target child in the preceding month relative to men (34.3\% versus $23.6 \%$, respectively). According to the Chi-Square analysis, this was the only significant difference in communication between mothers and fathers. The results from the Chi-Squares tests identify that there is only one dependent variable that shows a statistically significant difference between the incarcerated mothers and incarcerated fathers (visits). Thirty-four percent of the incarcerated mothers reported that they had at least one visit from the target child. Incarcerated fathers, on the other hand, reported that only $23.6 \%$ had at least one visit during the past month. This result does not support the hypothesis that incarcerated 
fathers will have more visits than incarcerated mothers, and is contrary to previous research which suggests that incarcerated fathers, rather than incarcerated mothers, are more likely to have a visit from their loved ones. But the competing hypothesis, suggesting that incarcerated mothers were more likely to have visits, was statistically significant. 
Table 4

Chi Squares Assessing Proportions of Gender and the Forms of Communication during the past month

\begin{tabular}{|c|c|c|c|c|c|}
\hline \multirow[b]{2}{*}{ Dependent Variables } & \multicolumn{2}{|c|}{ Males } & \multicolumn{2}{|c|}{ Females } & \multirow[b]{2}{*}{ Significance Test } \\
\hline & $\mathrm{N}$ & $\%$ & $\mathrm{~N}$ & $\%$ & \\
\hline Visits & & & & & $\chi^{2}=4.923^{*}$ \\
\hline Yes & 38 & 23.6 & 68 & 34.3 & \\
\hline No & 123 & 76.4 & 130 & 65.7 & \\
\hline Totals & 161 & & 198 & & \\
\hline Phone Calls & & & & & $\chi^{2}=1.634$ \\
\hline Yes & 81 & 50.3 & 113 & 57.1 & \\
\hline No & 80 & 49.7 & 85 & 42.9 & \\
\hline Totals & 161 & & 198 & & \\
\hline Letters received from $\mathrm{TC}^{1}$ & & & & & $\chi^{2}=1.946$ \\
\hline Yes & 67 & 41.6 & 97 & 49.0 & \\
\hline No & 94 & 58.4 & 101 & 51.0 & \\
\hline Totals & 161 & & 198 & & \\
\hline Letters sent to the TC & & & & & $\chi^{2}=.293$ \\
\hline Yes & 123 & 76.4 & 156 & 78.8 & \\
\hline No & 38 & 23.6 & 42 & 21.2 & \\
\hline Totals & 161 & & 198 & & \\
\hline Letters were sent and received & & & & & $\chi^{2}=1.815$ \\
\hline Yes & 65 & 40.4 & 94 & 47.5 & \\
\hline No & 96 & 59.6 & 104 & 52.5 & \\
\hline Totals & 161 & & 198 & & \\
\hline More than one type was used & & & & & $\chi^{2}=3.016$ \\
\hline Yes & 99 & 61.5 & 139 & 70.2 & \\
\hline No & 62 & 38.5 & 59 & 29.8 & \\
\hline Totals & 161 & & 198 & & \\
\hline All three Indirect Forms & & & & & $\chi^{2}=.501$ \\
\hline Yes & 133 & 82.6 & 169 & 85.4 & \\
\hline No & 28 & 17.4 & 29 & 14.6 & \\
\hline Totals & 161 & & 198 & & \\
\hline
\end{tabular}

${ }^{1}$ TC $=$ Target Child, ${ }^{*} \mathrm{p}<.05$ 


\section{Logistic Regressions}

Logistic regressions will show the impact and direction of the impact that the independent variable (incarcerated parent's sex) and the control variables (minority status, education, number of children, whether the incarcerated parent lived with at least one of their children prior to incarceration, age of the target child, whether the incarcerated parent had abused alcohol/drugs, the total length of their sentence, and how long the incarcerated parent had already served at the time of the baseline interview) have on the likelihood that the incarcerated parent will participate in each form of communication (visits, phone calls, receiving letters from the target child, sending letters to the target child, back-and-forth letter communication, utilization of more than one form of communication, and participation in all three forms of indirect communication). This type of analysis allows us to go deeper into explanations than the proportion analysis delivered through simple bivariate analysis. The results of the logistic regressions testing the influence of the incarcerated parent's sex on forms of communication are presented in nine models, with the 9th representing the overall model.

\section{Visits}

In this model, two of the predictors were statistically significant (See Table 5). As expected, one of those was the incarcerated parent's sex. Results from previous studies are mixed, and therefore, I formulated two competing hypotheses. The expectation was that incarcerated fathers would have utilized visits more than incarcerated mothers and vice versa. In this model, from the present study, incarcerated 
mothers were almost twice as likely to have a visit with the target child when compared to the incarcerated fathers. These results are consistent with those of the sample comparison of proportions shown in Table 3.

The other variable that reached statistical significance was whether the incarcerated parent had lived with at least one of their children prior to incarceration. Again, incarcerated parents who had lived with at least one of their children prior to incarceration were almost twice as likely to have a visit when compared to incarcerated parents who had not lived with at least one of their children prior to incarceration. The latter variable was the strongest predictor of at least one visit, with an odds ratio of 1.71 . This, however, was just slightly higher than the incarcerated parent's sex odds ratio (1.70). Interestingly, there were no statistically significant effects regarding the minority status or level of education. White incarcerated parents, with more education, are not significantly more likely to have a visit with the target child. See Appendix Table A.1, for all interim logistic regression model results. 
Table 5

Visits with the Target child

\begin{tabular}{lcl}
\hline & \multicolumn{2}{c}{ M9 } \\
Measures & $\mathrm{B}$ & $\mathrm{SE}$ \\
\hline Sex $($ Female $=1)$ & .53 & $.26^{*}$ \\
MS $^{1}($ White $=1)$ & .34 & .27 \\
Education & & \\
$\quad$ Less than HS Diploma & .04 & .31 \\
$\quad$ GED/HS Diploma & -.02 & .30 \\
Number of Children & -.10 & .06 \\
Lived with Children $(y e s=1)$ & .54 & $.25^{*}$ \\
Age of Target Child & .08 & .05 \\
Substance Abuse $(y e s=1)$ & .01 & .43 \\
Total Sentence Length & .35 & .41 \\
Length of Inc. at Base. & -.23 & .42 \\
Constant & -2.33 & $.70^{*}$ \\
\hline${ }^{*}$ p $<.05$ & & \\
${ }^{1}$ MS = Minority Status. The omitted MS category is Other =0. \\
${ }^{2}$ The omitted Education category is At least some college/College graduate = 3
\end{tabular}

\section{Phone Calls}

Two of the predictors were statistically significant: sex of the incarcerated parent and race (See Table 6). Incarcerated mothers are almost twice as likely to have at least one phone call during a month with the target child. This does not support the hypothesis that there would not be a statistically significant difference in the utilization of phone calls between incarcerated mothers and incarcerated fathers. The other statistically significant variable, race of the incarcerated parent, recorded an odds ratio of 1.76, which suggests that White incarcerated parents are almost twice as likely to have a phone call with the target child. See Appendix A.2 for all interim logistic regression model results. 
Table 6

Phone Calls with the Target Child

\begin{tabular}{lcl}
\hline & \multicolumn{2}{c}{ M9 } \\
Measures & B & SE \\
\hline Sex $($ Female = 1) & .48 & $.24^{*}$ \\
MS $^{1}($ White $=1)$ & .57 & $.24^{*}$ \\
Education & & \\
$\quad$ Less than HS Diploma & -.02 & .28 \\
$\quad$ GED/HS Diploma & .20 & .28 \\
Number of Children & -.04 & .5 \\
Lived with Children (yes = 1) & .36 & .23 \\
Age of Target Child & -.01 & .04 \\
Substance Abuse (yes = 1) & -.60 & .41 \\
Total Sentence Length & .64 & .39 \\
Length of Inc. at Base. & -.42 & .39 \\
Constant & -.49 & .63 \\
\hline${ }^{*}$ p $<.05$ & & \\
${ }^{1}$ MS = Minority Status. The omitted MS category is Other = 0. \\
${ }^{2}$ The omitted Education category is At least some college/College graduate = 3
\end{tabular}

\section{Letters received from Target Child}

Two of the predictors were statistically significant in the overall model (the total number of children and whether the incarcerated parent lived with their child prior to incarceration) (See Table 7). Interestingly, incarcerated parents with fewer children are more likely to receive a letter from the target child. The strongest predictor of receiving at least one letter from the target child was whether the incarcerated parent had lived with at least one of their children prior to incarceration, with an odds ratio of 1.69.This means that incarcerated parents who lived with at least one of their children prior to incarceration were almost twice as likely to receive at least one letter from the target child. Again, the results do not support the hypothesis that incarcerated mothers are more likely to receive letters from the target child, as an indication of previously established 
bonds, since more incarcerated mothers are expected to have lived with their children prior to incarceration. See Appendix A.3 for regression models analyzing the likelihood of receiving letters from the target child.

Table 7

Letters Received from the Target Child

\begin{tabular}{lcc}
\hline & \multicolumn{2}{c}{ M9 } \\
Measures & B & SE \\
\hline Sex $($ Female = 1) & .07 & .23 \\
MS $^{1}($ White $=1)$ & .16 & .24 \\
Education $^{2}$ & & \\
$\quad$ Less than HS Diploma & -.19 & .28 \\
$\quad$ GED/HS Diploma & .01 & .27 \\
Number of Children & -.12 & $.05^{*}$ \\
Lived with Children $(y e s=1)$ & .53 & $.23^{*}$ \\
Age of Target Child & .03 & .04 \\
Substance Abuse $(y e s=1)$ & .12 & .38 \\
Total Sentence Length & .35 & .38 \\
Length of Inc. at Base. & -.47 & .39 \\
Constant & -.43 & .62 \\
\hline
\end{tabular}

$* \mathrm{p}<.05$

${ }^{1} \mathrm{MS}=$ Minority Status. The omitted MS category is Other $=0$.

${ }^{2}$ The omitted Education category is At least some college/College graduate $=3$

\section{Letters sent to the Target Child}

Only one of the predictors was statistically significant: the total number of children (See Table 8). The negative relationship between the number of children and sending a letter to the target child suggests that incarcerated parents with fewer children are more likely to send at least one letter to the target child. In the original baseline data collection, this question may have been somewhat difficult to answer. Incarcerated parents may have sent letters for all their children and not just specifically the identified target child. An incarcerated parent may have also sent a letter, for a young target child, 
to an older child who was asked to read the letter to the target child. There may have been variation in how incarcerated parents responded to this question. The incarcerated parent's sex was not significant, which does not support the hypothesis that incarcerated mothers would be more likely than fathers to utilize letter writing (See A.4 for details of Models 1-9).

Table 8

Letters Sent to the Target Child

\begin{tabular}{lcc}
\hline & \multicolumn{2}{c}{ M9 } \\
Measures & B & SE \\
\hline Sex $($ Female $=1)$ & .05 & .29 \\
MS $^{1}($ White $=1)$ & .16 & .29 \\
Education & & \\
$\quad$ Less than HS Diploma & .06 & .33 \\
$\quad$ GED/HS Diploma & .16 & .33 \\
Number of Children & -.11 & $.06^{*}$ \\
Lived with Children $(y e s=1)$ & .39 & .28 \\
Age of Target Child & -.02 & .05 \\
Substance Abuse $($ yes $=1)$ & .18 & .46 \\
Total Sentence Length & .15 & .47 \\
Length of Inc. at Base. & -.43 & .47 \\
Constant & 1.08 & .73 \\
\hline
\end{tabular}

$* \mathrm{p}<.05$

${ }^{1} \mathrm{MS}=$ Minority Status. The omitted MS category is Other $=0$.

${ }^{2}$ The omitted Education category is At least some college/College graduate $=3$

\section{Letters being sent and received}

The previous two dependent variables looked separately at letters written by parents and those written by children and received by their parents (See Table 9). This analysis looks at written communication back-and-forth between the target child and parent. This measure indicates that the incarcerated parent sent a letter to the target child, and that the incarcerated parent also received a letter from the target child during the 
previous month. Only one of the predictors was statistically significant, and was also the strongest predictor that back-and-forth communication occurred: whether the incarcerated parent lived with at least one of their children prior to incarceration. Incarcerated parents who lived with at least one of their children prior to incarceration were almost twice as likely to send and receive at least one letter during the month prior to the interview (See Appendix A.5 for details of Models1-9). Once again, the expectation was that there would be a statistically significant difference between incarcerated fathers and incarcerated mothers in this form of back-and-forth communication, which was not supported.

Table 9

Letters Sent and Received

\begin{tabular}{lcc}
\hline & \multicolumn{2}{c}{ M9 } \\
Measures & B & SE \\
\hline Sex $($ Female $=1)$ & .09 & .23 \\
MS $^{1}($ White $=1)$ & .13 & .24 \\
Education $^{2}$ & & \\
$\quad$ Less than HS Diploma & -.21 & .28 \\
$\quad$ GED/HS Diploma & -.13 & .27 \\
Number of Children & -.10 & .05 \\
Lived with Children $(y e s=1)$ & .53 & $.23^{*}$ \\
Age of Target Child & .02 & .04 \\
Substance Abuse $(y e s=1)$ & .16 & .38 \\
Total Sentence Length & .11 & .38 \\
Length of Inc. at Base. & -.21 & .38 \\
Constant & -.34 & .61 \\
\hline
\end{tabular}

${ }^{*} \mathrm{p}<.05$

${ }^{1} \mathrm{MS}=$ Minority Status. The omitted MS category is Other $=0$.

${ }^{2}$ The omitted Education category is At least some college/College graduate $=3$ 


\section{More than one form of Communication}

The dependent variable in this model is assessing whether the incarcerated parent participated in more than one form of communication (See Table 10). Three of the predictors made a statistically significant contribution to the model (incarcerated parent's sex, total number of children, and whether the incarcerated parent lived with at least one of their children prior to incarceration). The strongest predictor of using more than one form of communication was if the incarcerated parent lived with at least one of their children prior to incarceration, with an odds ratio of 2.03. This indicates that incarcerated parents who lived with at least one of their children prior to incarceration were slightly more than twice as likely to use more than one form of communication with the target child. Incarcerated mothers were almost twice as likely to utilize more than one form of communication with the target child, and incarcerated parents with fewer children are .86 times as likely to utilize more forms of communication with the target child (See Appendix A.6 for details of Models 1-9). The statistically significant difference between incarcerated mothers and incarcerated fathers supports the hypothesis that incarcerated mothers are more likely to utilize multiple forms of communication with the target child in order to maintain their relationship. 
Table 10

More than one form of Communication

\begin{tabular}{|c|c|c|}
\hline \multirow[b]{2}{*}{ Measures } & \multicolumn{2}{|c|}{ M9 } \\
\hline & B & $\mathrm{SE}$ \\
\hline Sex $($ Female $=1)$ & .55 & $.26 *$ \\
\hline $\operatorname{MS}^{1}($ White $=1)$ & .21 & .26 \\
\hline Education $^{2}$ & & \\
\hline Less than HS Diploma & .34 & .30 \\
\hline GED/HS Diploma & .22 & .30 \\
\hline Number of Children & -.15 & $.05 *$ \\
\hline Lived with Children (yes $=1$ ) & .71 & $.25 *$ \\
\hline Age of Target Child & -.01 & .04 \\
\hline Substance Abuse (yes $=1$ ) & -.36 & .44 \\
\hline Total Sentence Length & .66 & .42 \\
\hline Length of Inc. at Base. & -.46 & .42 \\
\hline Constant & .14 & .67 \\
\hline
\end{tabular}

\section{Indirect Communication}

The indirect communication analyses examined whether the incarcerated parent participated in a phone call, sent a letter to the target child, and received a letter from the target child (See Table 11). Four of the predictors were statistically significant (total number of children, whether the incarcerated parent lived with at least one of their children prior to incarceration, total sentence length, and length of time already served at the baseline interview). The total number of children and the length of time served at the baseline both maintain a negative relationship with the likelihood of utilizing all forms of indirect communication, which indicates that incarcerated parents with fewer children and less time already served are more likely to utilize all forms of indirect communication with the target child. The strongest predictor of utilizing all three forms 
of indirect communication was the total length of the incarcerated parent's prison sentence, with an odds ratio of 5.24. This suggests that incarcerated parents with longer sentences are 5 times as likely to utilize all three forms of indirect communication. Again, the difference between incarcerated mothers' and incarcerated fathers' utilization of indirect communication is not statistically significant. Interestingly, there were competing hypotheses regarding whether mothers or fathers would use more forms of indirect communication, but neither hypothesis was supported (See A.7 for details of Models 1-

\section{9.).}

Table 11

Using all forms of Indirect Communication

\begin{tabular}{|c|c|c|}
\hline \multirow[b]{2}{*}{ Measures } & \multicolumn{2}{|c|}{ M9 } \\
\hline & $\mathrm{B}$ & SE \\
\hline Sex $($ Female $=1)$ & .29 & .34 \\
\hline $\operatorname{MS}^{1}($ White $=1)$ & .02 & .34 \\
\hline \multicolumn{3}{|l|}{ Education $^{2}$} \\
\hline Less than HS Diploma & .10 & .38 \\
\hline GED/HS Diploma & .44 & .41 \\
\hline Number of Children & -.17 & $.06 *$ \\
\hline Lived with Children (yes = 1) & .68 & $.34^{*}$ \\
\hline Age of Target Child & -.04 & .06 \\
\hline Substance Abuse (yes =1) & .61 & .54 \\
\hline Total Sentence Length & 1.66 & $.59 *$ \\
\hline Length of Inc. at Base. & -1.36 & $.58 *$ \\
\hline Constant & .45 & .85 \\
\hline
\end{tabular}




\section{Summary}

The results of the analyses are mixed, and provide insight into which factors have more influence on whether incarcerated mothers and fathers are utilizing different forms of communication with their children. Table 12 presents a summary of the hypotheses. 
Table 12

Summary of the Hypotheses Results from Model 9 of the Logistic Regressions

\begin{tabular}{|c|c|c|}
\hline & Results & Relevant Table \\
\hline $\begin{array}{l}\text { H1: Incarcerated mothers will utilize more forms of } \\
\text { communication. }\end{array}$ & $\begin{array}{l}\text { There were statistically } \\
\text { significant differences. } \\
\text { Incarcerated mothers } \\
\text { utilized more forms of } \\
\text { communication with the } \\
\text { target child }\end{array}$ & 10 \\
\hline $\begin{array}{l}\text { H2: Incarcerated fathers are expected to utilize visits more } \\
\text { than incarcerated mothers. }\end{array}$ & $\begin{array}{l}\text { There were statistically } \\
\text { significant differences. } \\
\text { But incarcerated mothers } \\
\text { had more visits with the } \\
\text { target child. }\end{array}$ & 5 \\
\hline $\begin{array}{l}\text { H4: Incarcerated mothers are expected to utilize visits more } \\
\text { than incarcerated fathers. }\end{array}$ & $\begin{array}{l}\text { There were statistically } \\
\text { significant differences. } \\
\text { Incarcerated mothers were } \\
\text { more likely to have a visit } \\
\text { with the target child. }\end{array}$ & \\
\hline $\begin{array}{l}\text { H3: Incarcerated mothers will utilize all forms of indirect } \\
\text { communication more than incarcerated fathers. }\end{array}$ & $\begin{array}{l}\text { No statistically significant } \\
\text { difference by Sex. }\end{array}$ & 11 \\
\hline $\begin{array}{l}\text { H4: Incarcerated fathers will utilize all forms of indirect } \\
\text { communication more than incarcerated mothers. }\end{array}$ & $\begin{array}{l}\text { No statistically significant } \\
\text { difference by Sex. }\end{array}$ & 11 \\
\hline $\begin{array}{l}\text { H5: Incarcerated mothers will utilize phone calls more than } \\
\text { incarcerated fathers. }\end{array}$ & $\begin{array}{l}\text { There were statistically } \\
\text { significant differences. } \\
\text { Incarcerated mothers were } \\
\text { more likely to have a } \\
\text { phone call with the target } \\
\text { child. }\end{array}$ & 6 \\
\hline $\begin{array}{l}\text { H6: Incarcerated mothers are more likely to send a letter to } \\
\text { the target child than incarcerated fathers. }\end{array}$ & $\begin{array}{l}\text { No statistically significant } \\
\text { difference by Sex. }\end{array}$ & 8 \\
\hline $\begin{array}{l}\text { H7: Incarcerated mothers are more likely to receive a letter } \\
\text { from the target child than incarcerated fathers. }\end{array}$ & $\begin{array}{l}\text { No statistically significant } \\
\text { difference by Sex. }\end{array}$ & 7 \\
\hline $\begin{array}{l}\text { H8: Incarcerated mothers are more likely to both send and } \\
\text { receive letters than the incarcerated fathers. }\end{array}$ & $\begin{array}{l}\text { No statistically significant } \\
\text { difference by Sex. }\end{array}$ & 8 \\
\hline
\end{tabular}




\section{Discussion}

Using data from the baseline survey of Oregon Social Learning Center’s (OSLC) larger study, the present study found that the sex of the incarcerated parent does play significant roles in some forms of communication with the identified target children. Bivariate analysis identified a statistically significant difference in the sex of the incarcerated parent and the likelihood of participating in a visit with the target child: incarcerated mothers are more likely to have had at least one visit with the target child. Multivariate analysis highlighted this same result, but also showed inconsistent results regarding the other communication types. In the final multivariate models, the incarcerated mothers were significantly more likely to participate in a visit, phone call, and to utilize more than one form of communication with the target child. Incarcerated fathers were not more likely to participate in any of the forms of the communication, when compared to the incarcerated mothers. The incarcerated parent's sex was not statistically significant in any of the models examining the likelihood that a letter would be received from the target child, whether a letter was sent to the target child, whether there was back-and-forth letter communication with the target child, and whether all forms of indirect communication were utilized with the target child. This finding suggests that there are other factors influencing the likelihood of letter writing.

Other interesting findings were the minimal impacts of minority status, educational attainment, and substance abuse on the likelihood of communication between the incarcerated parent and the target child. Minority status was statistically significant 
with only one dependent variable. White incarcerated parents were almost twice as likely to have at least one phone call with the target child. The results reflected that with all the other dependent communication variables, White incarcerated parents were more likely to have utilized the varied forms of communication, but the results were not statistically significant. Similarly, educational attainment was not statistically significant in any of the regression models (Models 1-9). There were also mixed results in terms of which levels of educational attainment were more likely to influence utilization of the varied forms of communication. Substance abuse also presented mixed results, none of which were statistically significant. Substance abuse was not statistically significant in any of the models, for any of the communication variables. Interestingly, in some models those who had substance abuse issues were more likely to communicate with the target child, while in other models those who did not have a history of substance abuse were more likely to communicate with the target child. See Appendix A for results of all logistic regression models for each of the dependent variables.

The present study was limited by the formatting of the baseline questions asked in the original OSLC study. The wording of some of the questions may have influenced some outcomes. While the original study focused on one specific target child, the baseline data, which was utilized for the present study, contained questions that were not focused on the target child. Therefore, the present study cannot say, without a doubt, that the responses to some questions were specific to the target child. A future study should evaluate communication between incarcerated parents and all their children, including 
analyses which examine the differences between children that the incarcerated parent was living with prior to incarceration, and those children that the incarcerated parent was not living with prior to incarceration. Caretaker demographics also need to be considered in future studies. Specifically, does the relationship of the caretaker to the incarcerated parent affect the communication efforts between those children and the incarcerated parent? Future studies will also want to examine communication types in continuous variables over a longer period of time. For instance, are there differences in the frequency patterns of communications between mothers and fathers? While there are many other variables that could be included in future analyses, the present study did highlight that there are, in fact, differences in how incarcerated mothers and incarcerated fathers communicate with their children.

Oregon, for example, has fourteen facilities where inmates are housed. Only one of these facilities houses women offenders. One might assume that communication between incarcerated mothers and their children may be much more difficult because the caregivers and the children may be coming from different parts of the state. Yet, the analysis from the present study identifies that the target children are more likely to visit incarcerated mothers. This may be because of Oregon’s population disbursement. The majority of Oregon residents live on the west side of the state, which is where the female facility is located. Therefore, female inmates may not be as impacted by the location of their facility, possibly accounting for the discrepancy of this finding with the prior literature. Incarcerated fathers in an eastern facility may in actuality be the most isolated 
population of Oregon inmates (U.S. Census Bureau, 2010). Male offenders, however, for the purpose of this study were able to transfer between institutions in order to participate in the study (J.M. Eddy, personal communication, May 1, 2012). A future study should examine contextualizing variables from the caregivers in order to analyze the time and financial impact of visiting and maintaining phone call communication with the incarcerated parent.

In addition to the influence of gender differences on incarcerated parent communication overall, research is needed on special populations of inmate parents. For example, the population of incarcerated veterans is growing, and a future study should examine whether prior military service plays a role in communication with their children. One hypothesis is that separation, due to deployment, may have already created a pattern utilizing indirect forms of communication. Another study might examine the differences in living arrangements for children of incarcerated parents. Are there communication differences for children who are living with the other parent/step-parent versus those children living with other relatives or in foster care? Since Oregon is not racially diverse, how are incarcerated parents, who are a part of the very small racial subgroups, affected by their ability/inability to communicate with their children? Are these effects generalizable to other states? Finally, previous literature suggests that children of incarcerated parents are at increased risk of themselves becoming incarcerated (Dallaire, 2007; Luke, 2002). Are there differences in how incarcerated parents communicate with 
their children who have had interaction with the juvenile criminal justice system versus those children who have not engaged in criminal behaviors?

Future research should continue to focus on identifying the hardships and complexities of maintaining communicating with incarcerated loved ones during periods of incarceration. For example, the present study did not assess the influence of offense type on which forms of communication were utilized by the incarcerated parent with the target child. Does the type of offense committed by the incarcerated parent influence the likelihood of communication with children? Another study might examine how the custody level of the incarcerated parent effects communication with their children. The literature suggests that, generally, communication between incarcerated parents and their children is positive and can mitigate all of the negative effects of having an incarcerated parent (Cunningham, 2001; Dallaire, Ciccone, \& Wilson, 2010; Hairston, 2002; Harris \& Pettway, 2007; Loper \& Tuerk, 2006; Meek, 2007; Nickel, Garland, \& Kane, 2009; Poehlmann, Dallaire, Loper, \& Shear, 2010). But is this always the case? Another line of research should examine the influence of domestic violence and whether all communication is good communication, or if there needs to be specialized parenting classes or communication classes regarding how to rebuild those damaged relationships. I also suggest a qualitative examination of Oregon’s inmates to determine the ease with which they are able to communicate with their loved ones. A future study could survey inmates and their families from all of the ODOC facilities. This study could focus on the varied communication patterns between incarcerated parents living on the west aside of 
the state versus those more isolated in the eastern part of the state. Since Oregon has only one women's facility, which is located within the most populated area of Oregon, there may be unique patterns associated with female inmates and their loved ones. A comparison study could examine the location of women's prisons, and how the location effects the children's ability to stay connected to their incarcerated mothers. Previous studies suggest that communication assists inmates in getting through their time, and then most importantly, helps them successfully reintegrate back into society. We should be actively ensuring that healthy, positive, and safe communication opportunities between inmates and their loved ones are available to all inmates.

Aside from the stress of being separated from their families, prison life and adjustment to prison life bring increased stress to incarcerated parents. Studies suggest that decreasing stress associated with being a parent allows an incarcerated mother or father to better adjust to prison life (Bearse, 2008; Loper \& Tuerk, 2006). Particularly, increased amounts of letter writing have been shown to significantly decrease parental stress (Loper \& Tuerk, 2006). And congruently, continued contact with incarcerated parents has been shown to decrease the negative effects on children of having a parent incarcerated (Nickel, Garland, \& Kane, 2009). Further examination regarding how incarcerated mothers and incarcerated fathers communicate with their children will lead to increased understanding and ability to assist incarcerated parents in their communication efforts, in the hopes of decreasing the negative impacts of family separation. 


\section{References}

Arditti, J.A. (2005). Families and incarceration: An ecological approach. The Journal of Contemporary Social Services, 86, 251-260.

Arditti, J.A. (2003). Locked doors and glass walls: Family visiting at a local jail. Journal of Loss and Trauma, 8, 115-138. doi: 10.1080/15325020390168735

Arditti, J.A., \& Few, A.L. (2008). Maternal distress and women’s reentry into family and community life. Family Process, 47, 303-321.

Arditti, J.A., \& Few, A.L. (2006). Mothers’ reentry into family life following incarceration. Criminal Justice Policy Review, 17, 103-123. doi: $10.1177 / 0887403405282450$

Arditti, J.A., Lambert-Shute, J., \& Joest, K. (2003). Saturday morning at the jail: Implications of incarceration for families and children. Family Relations, 52(3), 195-204.

Arditti, J.A., Smock, S.A., Parkman, T.S. (2005). “It's been hard to be a father”: A qualitative exploration of incarcerated fatherhood. Fathering, 3, 267-288.

Bearse, M.L. (2008, June). Children and families of incarcerated parents: Understanding the challenges and addressing the needs. Report to the Children and Families of Incarcerated Parents Advisory Committee. Retrieved from http://www.dshs.wa.gov/pdf/incarcerated/CFIPfinal.pd

Celinska, K., \& Siegel, J.A. (2010). Mothers in trouble: Coping with actual or pending separation from children due to incarceration. The Prison Journal, 90(4), 447474. doi: $10.1177 / 00.28855103282218$

Cunningham, A. (2001). Forgotten families: The impacts of imprisonment. Family 
Matters, 59, 35-38.

Dallaire, D.H. (2007). Incarcerated mothers and fathers: A comparison of risks for children and families. Family Relations, 56, 440-453.

Dallaire, D.H., Ciccone, A., \& Wilson, L.C. (2010). Teachers’ experiences with and expectations of children with incarcerated parents. Journal of Applied Developmental Psychology, 31, 281-290. doi: 10.1016/j.appdev.2010.04.001.

Duwe, G., \& Clark, V. (2011). Blessed be the social tie that binds: The effects of prison Visitation on offender recidivism. Criminal Justice Policy Review, 1-26. doi: $10.1177 / 0887403411429724$

Eddy, J.M., Martinez, C.R., Schiffmann, T., Newton, R., Olin, L., Leve, L., Foney, D.M., \& Shortt, J.W. (2008). Development of a multisystemic parent management training intervention for incarcerated parents, their children and families. Clinical Psychologist, 12, 86-98. doi: 10.1080/13284200802495461.

Glaze, L.E., \& Maruschak, L.M. (2010). Parents in prison and their minor children. (Research Report NCJ 222984). Retrieved from http://bjs.ojp.usdoj.gov/index.cfm?ty=pbdetail\&iid=823

Gonzalez, P., Romero, T., \& Cerbana, C.B. (2007). Parent education programs for incarcerated mothers in Colorado. The Journal of Correctional Education, 58(4), 357-373. issn: 07402708.

Gray, T., Mays, G.L., \& Stohr, M.K. (1995). Inmate needs and programming in exclusively women's jails. The Prison Journal, 75, 186-202.

Grella, C.E., \& Greenwell, L. (2006). Correlates of parental status and attitudes toward parenting among substance-abusing women offenders. The Prison Journal, 86(1), 
89-113. doi: 10.1177/0032885505283925.

Grinstead, O., Faigeles, B., Bancroft, C., \& Zack, B. (2001). The financial cost of maintaining relationships with incarcerated African American men: A survey of women prison visitors. Journal of African American Men, 6, 59-70.

Hairston, C.F. (2007). Focus on Children with incarcerated parents: An overview of the I research literature. Retrieved from the Annie E. Casey Foundation website: http://www.annie.e.caseyfoundation.org/ /media/Pubs/Topics/Special\%20Interest \%20Areas/Incarceration\%20and\%20Reentry/FocusonChildrenwithIncarceratedPa rentsAnOverv/HAIRSTON.pdf

Hairston, J.C.F. (2002, January). Prisoners and families: Parenting issues during incarceration.Paper presented at the U.S. Department of Health and human Services conference, “From Prison to Home” Paper retrieved from http://aspe.hhs.gov/hsp/prison2home02/Hairston.htm

Harris, M., \& Pettaway, C. (2007). Best practices tool-kit: Incarcerated parents and parenting programs. Retrieved from Ohio Department of Rehabilitation and Correction's website: http://www.drc.ohio.gov/web/iej_files/ToolKit\%20Incarcerated\%20Parents\%20a nd\%20Parenting\%20Programs.pdf

Hoffman, H.C., Byrd, A.L., Kightlinger, A.M. (2010). Prison programs and services for incarcerated parents and their underage children: Results from a national survey of correctional facilities. The Prison Journal, 90(4), 397-416. Doi: 10.1177/0032885510382087.

Houck, K.D.F., \& Loper, A.B. (2002). The relationship of parenting stress to adjustment 
among mothers in prison. American Journal of Orthopsychiatry, 72(4), 548-558. doi: 10.1037//0002-9432.72.4.548.

Jiang, S., \& Winfree, L.T. (2006). Social support, gender, and inmate adjustment to prison life: Insights from a national sample. The Prison Journal, 86, 32-55.

Johnson, E.I., \& Waldfogel, J. (2002). Parental incarceration: Recent trends and implications for child welfare. Social Service Review, 76, 460-479.

Kennon, S.S., Mackintosh, V.H., \& Myers, B.J. (2009). Parenting education for incarcerated mothers. Journal of Correctional Education, 60(1), 10-30. issn: 07402708.

La Vigne, N.G., Davies, E., \& Brazzell. (2008). Broken bonds: Understanding and addressing the needs of children with incarcerated parents. Urban Institute Justice Policy Center.

La Vigne, N.G., Naser, R.L., Brooks, L.E., \& Castro, J.L. (2005). Examining the effect of incarceration and in-prison contact on prisoners’ family relationships. Journal of Contemporary Criminal Justice, 21, 314-335. doi: 10.1177/1043986205281727

Loper, A.B., Carlson, L.W., Levitt, L., \& Scheffel, K. (2009). Parenting stress, alliance, child contact, and adjustment of imprisoned mothers and fathers. Journal of Offender Rehabilitation, 48(6), 483-503. doi: 10.1080/10509670903081300.

Loper, A.B., \& Tuerk, E.H. (2011). Improving the emotional adjustment and communication patterns of incarcerated mothers: Effectiveness of a prison parenting intervention. Criminal Justice Policy Review, 20(1), 89-101.

Loper, A.B., \& Tuerk, E.H. (2006). Parenting programs for incarcerated parents: Current research and future directions. Criminal Justice Policy Review, 17(4), 407-427. 
Luke, K.P. (2002). Mitigating the ill effects of maternal incarceration on women in prison and their children. Child Welfare League of America, 81, 929-948.

McGrath, E. (2012). Reentry courts: Providing a second chance for incarcerated mothers and their children. Family Court Review, 50, 113-127.

Meek, R. (2007). Parenting education for young fathers in prison. Child and Family Social Work, 12, 239-247.

Murray, J. (2005). The effects of imprisonment on families and children of prisoners. In A. Liebling \& S. Maruna (Eds.), The effects of imprisonment (442-462). Portland, OR: Wilan Publishing.

Murray, J., Farrington, D.P., Sekol, I., \& Olsen, R.F. (2010). Effects of parental imprisonment on child antisocial behaviour and mental health: A systematic review. (Research Report No. 229378). Washington, D.C.: USDOJ. Retrieved from the U.S. Department of Justice https://www.ncjrs.gov/pdffiles1/nij/grants/229378.pdf

Nickel, J., Garland, C., \& Kane, L. (2009). Children of incarcerated parents: An action plan for federal policymakers. Council of State Governments Justice Center. Retrieved from http://www.reentrypolicy.org/jc_publications/federa_action_plan_

Oregon Department of Corrections. (2011, January 19). Children of incarcerated parents project. Retrieved from http://www.oregon.gov/DOC/TRANS/PROGMS/oam_children.shtml Pettway, C., Dorsey, R., \& Byorth, B. (2004). Incarcerated fathers: A statistical profile. 
Retrieved from Ohio Department of Rehabilitation and Correction's website: http://www.drc.state.oh.us/web/reports/IncarceratedFathers.pdf

Poehlmann, J., Dallaire, D., Loper, A.B., \& Shear, L.D. (2010). Children’s contact with their incarcerated parents: Research findings and recommendations. American Psychologist, 65, 575-598. doi: 10.1037/a0020279

Poehlmann, J., \& Eddy, J.M. (Eds.). (2012). Relationship processes and resilience in children with incarcerated parents. In Press. Shared by J.M. Eddy.

Pollock, J.M. (2002). Women, prison, and crime. Belmont, CA: Wadsworth.

Shlafer, R.J., \& Poehlmann, J. (2010). Attachment and caregiving relationships in families affected by parental incarceration. Attachment and Human Development, 12, 395-415. doi:10.1080/14616730903417052

Tasca, M., Rodriguez, N., \& Zatz, M.S. (2011). Family and residential instability in the context of paternal and maternal incarceration. Criminal Justice and Behavior, 38(3), 231-247. doi: 10.1177/0093854810391632

Trice, A.D., \& Brewster, J. (2004). The effects of maternal incarceration on adolescent children. Journal of Police and Criminal Psychology, 19, 27-35.

Tuerk, E.H., \& Loper, A.B. (2006) Contact between incarcerated mothers and their children: Assessing parenting stress. Journal of Offender Rehabilitation, 43(1), 23-43. doi: 10.1300/J076v43n01_02.

U.S. Census Bureau. (2012). State \& county quick facts: Oregon. Retrieved from http://quickfacts.census.gov/qfd/states/41000.html

U.S. Census Bureau. (2010). 2010 census interactive population search. Retrieved from http://2010.census.gov/2010census/popmap/ 
van de Rakt, M., Murray, J., \& Nieuwbeerta. (2012). The long-term effects of paternal imprisonment on criminal trajectories of children. Journal of Research in Crime and Delinquency, 49, 81-108. Doi: 10.1177/0022427810393018

Visher, C.A., \& Travis, J. (2003). Transitions from prison to community: Understanding individual pathways. Annual Review of Sociology, 29, 89-113.

Wilson, K., Gonzalez, P., Romero, T., Henry, K., \& Cerbana, C. (2010). The effectiveness of parent education for incarcerated parents: An evaluation of parenting from prison. The Journal of Correctional Education, 61(2), 114-132. 
Appendix A.1

Logistic Regressions of Visits with the Target Child

\begin{tabular}{|c|c|c|c|c|c|c|c|c|c|c|}
\hline \multirow[b]{2}{*}{ Measures } & \multicolumn{2}{|c|}{ M5 } & \multicolumn{2}{|c|}{ M6 } & \multicolumn{2}{|c|}{ M7 } & \multicolumn{2}{|c|}{ M8 } & \multicolumn{2}{|c|}{ M9 } \\
\hline & $\beta$ & SE & $\beta$ & SE & $\beta$ & SE & $\beta$ & SE & $\beta$ & SE \\
\hline $\operatorname{Sex}^{1}$ & .49 & $.25 *$ & .42 & .25 & .43 & .25 & .54 & $.26^{*}$ & .53 & $.26 *$ \\
\hline $\mathrm{MS}^{2}$ & .30 & .26 & .30 & .26 & .31 & .26 & .33 & .26 & .34 & .27 \\
\hline \multicolumn{11}{|l|}{ Education $^{3}$} \\
\hline $\begin{array}{l}\text { Less than } \\
\text { HS Diploma }\end{array}$ & .07 & .30 & -.03 & .30 & -.02 & .30 & .04 & .31 & .04 & .31 \\
\hline $\begin{array}{l}\text { GED/HS } \\
\text { Diploma }\end{array}$ & .04 & .29 & -.03 & .30 & -.04 & .30 & -.03 & .30 & -.02 & .30 \\
\hline $\begin{array}{l}\text { Number of } \\
\text { Children }\end{array}$ & -.12 & .06 & -.12 & $.06 *$ & -.12 & $.06^{*}$ & -.10 & .06 & -.10 & .06 \\
\hline $\begin{array}{l}\text { Lived with } \\
\text { Children } \\
(\text { yes }=1)\end{array}$ & .48 & $.24 *$ & .52 & $.25 *$ & .51 & $.25^{*}$ & .53 & $.25^{*}$ & .54 & $.25 *$ \\
\hline $\begin{array}{l}\text { Age of Target } \\
\text { Child }\end{array}$ & & & .09 & $.04 *$ & .09 & $.04 *$ & .08 & .05 & .08 & .05 \\
\hline $\begin{array}{l}\text { Substance } \\
\text { Abuse } \\
(\text { yes }=1)\end{array}$ & & & & & -.11 & .41 & -.01 & .42 & .01 & .43 \\
\hline $\begin{array}{l}\text { Total } \\
\text { Sentence } \\
\text { Length }\end{array}$ & & & & & & & .13 & .08 & .35 & .41 \\
\hline $\begin{array}{l}\text { Length of Inc. } \\
\text { at Base. }\end{array}$ & & & & & & & & & -.23 & .42 \\
\hline Constant $^{4}$ & -1.21 & $.37 *$ & -1.86 & $.50^{* *}$ & -1.77 & $.60 *$ & -2.21 & $.66^{*}$ & -2.33 & $.70 *$ \\
\hline
\end{tabular}

${ }^{*} \mathrm{p}<.05, * * \mathrm{p}<.000$

${ }^{1}$ Sex: Female $=1$, Male $=0$

${ }^{2} \mathrm{MS}=$ Minority Status. The omitted MS category is Other $=0$.

${ }^{3}$ The omitted Education category is At least some college $=3$.

${ }^{4} \mathrm{M} 1-3$ were $\mathrm{p}<.001$, and M4 was $\mathrm{p}<.05$ 
Appendix A.2

Logistic Regressions of Phone Calls with the TC

\begin{tabular}{|c|c|c|c|c|c|c|c|c|c|c|}
\hline \multirow[b]{2}{*}{ Measures } & \multicolumn{2}{|c|}{ M5 } & \multicolumn{2}{|c|}{ M6 } & \multicolumn{2}{|c|}{ M7 } & \multicolumn{2}{|c|}{ M8 } & \multicolumn{2}{|c|}{ M9 } \\
\hline & $\beta$ & $\mathrm{SE}$ & $\beta$ & $\mathrm{SE}$ & $\beta$ & $\mathrm{SE}$ & $\beta$ & $\mathrm{SE}$ & $\beta$ & SE \\
\hline $\operatorname{Sex}^{1}$ & .25 & .22 & .25 & .22 & .30 & .23 & .51 & $.24^{*}$ & .48 & $.24 *$ \\
\hline $\mathrm{MS}^{2}$ & .44 & .23 & .45 & .23 & .52 & $.24 *$ & .56 & $.24^{*}$ & .57 & $.24 *$ \\
\hline \multicolumn{11}{|l|}{ Education $^{3}$} \\
\hline $\begin{array}{l}\text { Less than } \\
\text { HS } \\
\text { Diploma }\end{array}$ & -.14 & .27 & -.14 & .27 & -.13 & .27 & -.03 & .28 & -.02 & .28 \\
\hline $\begin{array}{l}\text { GED/HS } \\
\text { Diploma }\end{array}$ & .04 & .27 & .04 & .27 & -.02 & .27 & .01 & .28 & .20 & .28 \\
\hline $\begin{array}{l}\text { Number of } \\
\text { Children }\end{array}$ & -.06 & .05 & -.06 & .05 & -.06 & .05 & -.03 & .05 & -.04 & .5 \\
\hline $\begin{array}{l}\text { Lived with } \\
\text { Children } \\
(\text { yes = 1) }\end{array}$ & .35 & .23 & .35 & .23 & .31 & .23 & .35 & .23 & .36 & .23 \\
\hline $\begin{array}{l}\text { Age of Target } \\
\text { Child }\end{array}$ & & & .01 & .04 & .01 & .04 & -.00 & .04 & -.01 & .04 \\
\hline $\begin{array}{l}\text { Substance } \\
\text { Abuse } \\
(\text { yes = 1) }\end{array}$ & & & & & -.72 & .39 & -.63 & .41 & -.60 & .41 \\
\hline $\begin{array}{l}\text { Total } \\
\text { Sentence } \\
\text { Length }\end{array}$ & & & & & & & .24 & $.09 *$ & .64 & .39 \\
\hline $\begin{array}{l}\text { Length of Inc. } \\
\text { at Base. }\end{array}$ & & & & & & & & & -.42 & .39 \\
\hline Constant $^{4}$ & -.14 & .32 & -.20 & .43 & .40 & .55 & -.28 & .60 & -.49 & .63 \\
\hline
\end{tabular}

${ }^{*} \mathrm{p}<.05$

${ }^{1}$ Sex: Female $=1$, Male $=0$

${ }^{2} \mathrm{MS}=$ Minority Status. The omitted MS category is Other $=0$.

${ }^{3}$ The omitted Education category is At least some college $=3$.

${ }^{4} \mathrm{M} 1-4$ were not statistically significant 
Appendix A.3

Logistic Regressions of Letters Received from the Target Child

\begin{tabular}{|c|c|c|c|c|c|c|c|c|c|c|}
\hline \multirow[b]{2}{*}{ Measures } & \multicolumn{2}{|c|}{ M5 } & \multicolumn{2}{|c|}{ M6 } & \multicolumn{2}{|c|}{ M7 } & \multicolumn{2}{|c|}{ M8 } & \multicolumn{2}{|c|}{ M9 } \\
\hline & $\beta$ & $\mathrm{SE}$ & $\beta$ & SE & $\beta$ & SE & $\beta$ & $\overline{S E}$ & $\beta$ & $\overline{S E}$ \\
\hline $\operatorname{Sex}^{1}$ & .21 & .22 & .19 & .22 & .18 & .23 & .10 & .23 & .07 & .23 \\
\hline $\mathrm{MS}^{2}$ & .17 & .23 & .17 & .23 & .15 & .24 & .15 & .24 & .16 & .24 \\
\hline \multicolumn{11}{|l|}{ Education $^{3}$} \\
\hline $\begin{array}{l}\text { Less than } \\
\text { HS } \\
\text { Diploma }\end{array}$ & -.13 & .27 & -.15 & .27 & -.16 & .27 & -.20 & .28 & -.19 & .28 \\
\hline $\begin{array}{l}\text { GED/HS } \\
\text { Diploma }\end{array}$ & .02 & .27 & -.00 & .27 & .01 & .27 & .00 & .27 & .01 & .27 \\
\hline $\begin{array}{l}\text { Number of } \\
\text { Children }\end{array}$ & -.10 & $.05 *$ & -.10 & .05 & -.10 & $.05^{*}$ & -.12 & $.05^{*}$ & -.12 & $.05 *$ \\
\hline $\begin{array}{l}\text { Lived with } \\
\text { Children } \\
(\text { yes = 1) }\end{array}$ & .50 & $.22 *$ & .51 & $.23 *$ & .52 & $.23 *$ & .51 & $.23 *$ & .53 & $.23 *$ \\
\hline $\begin{array}{l}\text { Age of Target } \\
\text { Child }\end{array}$ & & & .03 & .04 & .03 & .04 & .03 & .04 & .03 & .04 \\
\hline $\begin{array}{l}\text { Substance } \\
\text { Abuse } \\
(\text { yes = 1) }\end{array}$ & & & & & .15 & .38 & .08 & .38 & .12 & .38 \\
\hline $\begin{array}{l}\text { Total } \\
\text { Sentence } \\
\text { Length }\end{array}$ & & & & & & & -.10 & .08 & .35 & .34 \\
\hline $\begin{array}{l}\text { Length of Inc. } \\
\text { at Base. }\end{array}$ & & & & & & & & & -.47 & .39 \\
\hline Constant $^{4}$ & -.20 & .32 & -.38 & .44 & -.50 & .54 & -.20 & .58 & -.43 & .62 \\
\hline
\end{tabular}

${ }^{*} \mathrm{p}<.05$

${ }^{1}$ Sex: Female $=1$, Male $=0$

${ }^{2}$ MS $=$ Minority Status. The omitted MS category is Other $=0$.

${ }^{3}$ The omitted Education category is At least some college $=3$.

${ }^{4} \mathrm{M} 1, \mathrm{M} 3$, and M4 were not statistically significant. M2 $\mathrm{p}<.05$ 
Appendix A.4

Logistic Regressions of Letters Sent to the Target Child

\begin{tabular}{|c|c|c|c|c|c|c|c|c|c|c|}
\hline \multirow[b]{2}{*}{ Measures } & \multicolumn{2}{|c|}{ M5 } & \multicolumn{2}{|c|}{ M6 } & \multicolumn{2}{|c|}{ M7 } & \multicolumn{2}{|c|}{ M8 } & \multicolumn{2}{|c|}{ M9 } \\
\hline & $\beta$ & SE & $\beta$ & SE & $\beta$ & SE & $\beta$ & $\mathrm{SE}$ & $\beta$ & SE \\
\hline $\operatorname{Sex}^{1}$ & .04 & .27 & .05 & .27 & .04 & .27 & .07 & .29 & .05 & .29 \\
\hline $\mathrm{MS}^{2}$ & .16 & .28 & .16 & .28 & .15 & .29 & .15 & .29 & .16 & .29 \\
\hline \multicolumn{11}{|l|}{ Education $^{3}$} \\
\hline $\begin{array}{l}\text { Less than } \\
\text { HS } \\
\text { Diploma }\end{array}$ & .03 & .33 & .04 & .33 & .04 & .33 & .06 & .33 & .06 & .33 \\
\hline $\begin{array}{l}\text { GED/HS } \\
\text { Diploma }\end{array}$ & .13 & .33 & .14 & .33 & .15 & .33 & .15 & .33 & .16 & .33 \\
\hline $\begin{array}{l}\text { Number of } \\
\text { Children }\end{array}$ & -.11 & $.05^{*}$ & -.11 & $.05^{*}$ & -.11 & $.05 *$ & -.11 & .06 & -.11 & $.06^{*}$ \\
\hline $\begin{array}{l}\text { Lived with } \\
\text { Children } \\
(\text { yes = 1) }\end{array}$ & .36 & .28 & .36 & .28 & .36 & .28 & .37 & .28 & .39 & .28 \\
\hline $\begin{array}{l}\text { Age of Target } \\
\text { Child }\end{array}$ & & & -.01 & .05 & -.01 & .05 & -.02 & .05 & -.02 & .05 \\
\hline $\begin{array}{l}\text { Substance } \\
\text { Abuse (yes = } \\
\text { 1) }\end{array}$ & & & & & .12 & .45 & .15 & .45 & .18 & .46 \\
\hline $\begin{array}{l}\text { Total Sentence } \\
\text { Length }\end{array}$ & & & & & & & .04 & .09 & .15 & .47 \\
\hline $\begin{array}{l}\text { Length of Inc. } \\
\text { at Base. }\end{array}$ & & & & & & & & & -.43 & .47 \\
\hline Constant $^{4}$ & 1.40 & $.38 *$ & 1.50 & $.53 *$ & 1.40 & $.64^{*}$ & 1.29 & .69 & 1.08 & .73 \\
\hline
\end{tabular}

${ }^{*} \mathrm{p}<.05$

${ }^{1}$ Sex: Female $=1$, Male $=0$

${ }^{2} \mathrm{MS}=$ Minority Status. The omitted MS category is Other $=0$.

${ }^{3}$ The omitted Education category is At least some college $=3$.

${ }^{4}$ M1-5 were $\mathrm{p}<.05$ 
Appendix A.5

Logistic Regressions of whether letters were both sent and received between the incarcerated parent and Target Child $\begin{array}{lllll}\text { M5 } & \text { M6 } & \text { M7 } & \text { M8 } & \text { M9 }\end{array}$

\begin{tabular}{lllllllllll} 
Measures & $\beta$ & SE & $\beta$ & SE & $\beta$ & SE & $\beta$ & SE & $\beta$ & SE \\
\cline { 2 - 10 } & .20 & .22 & .18 & .22 & .17 & .23 & .10 & .23 & .09 & .23 \\
Sex $^{1}$ & .15 & .23 & .15 & .23 & .13 & .24 & .12 & .24 & .13 & .24
\end{tabular}

Education $^{3}$

\begin{tabular}{|c|c|c|c|c|c|c|c|c|c|c|}
\hline $\begin{array}{l}\text { Less than } \\
\text { HS } \\
\text { Diploma }\end{array}$ & -.16 & .27 & -.17 & .27 & -.18 & .27 & -.22 & .28 & -.21 & .28 \\
\hline $\begin{array}{l}\text { GED/HS } \\
\text { Diploma }\end{array}$ & -.13 & .27 & -.14 & .27 & -.12 & .27 & -.13 & .27 & -.13 & .27 \\
\hline $\begin{array}{l}\text { Number of } \\
\text { Children }\end{array}$ & -.08 & .05 & -.08 & .05 & -.09 & .05 & -.10 & .05 & -.10 & .05 \\
\hline $\begin{array}{l}\text { Lived with } \\
\text { Children } \\
(\text { yes = 1) }\end{array}$ & .51 & $.22 *$ & .52 & $.22 *$ & .53 & $.23 *$ & .52 & $.23 *$ & .53 & $.23^{*}$ \\
\hline $\begin{array}{l}\text { Age of Target } \\
\text { Child }\end{array}$ & & & .01 & .04 & .01 & .04 & .02 & .04 & .02 & .04 \\
\hline $\begin{array}{l}\text { Substance } \\
\text { Abuse } \\
(\text { yes }=1)\end{array}$ & & & & & .20 & .38 & .14 & .38 & .16 & .38 \\
\hline $\begin{array}{l}\text { Total Sentence } \\
\text { Length }\end{array}$ & & & & & & & -.09 & .08 & .11 & .38 \\
\hline $\begin{array}{l}\text { Length of Inc. } \\
\text { at Base. }\end{array}$ & & & & & & & & & -.21 & .38 \\
\hline Constant $^{4}$ & -.24 & .32 & -.34 & .43 & -.50 & .54 & -.23 & .58 & -.34 & .61 \\
\hline
\end{tabular}

${ }^{*} \mathrm{p}<.05$

${ }^{1}$ Sex: Female $=1$, Male $=0$

${ }^{2} \mathrm{MS}=$ Minority Status. The omitted MS category is Other $=0$.

${ }^{3}$ The omitted Education category is At least some college $=3$.

${ }^{4} \mathrm{M} 1$ and 2 were $\mathrm{p}<.05$. M3 and 4 were not statistically significant. 
Appendix A.6

Logistic Regression of whether more than one form of communication was utilized

\begin{tabular}{|c|c|c|c|c|c|c|c|c|c|c|}
\hline \multirow[b]{2}{*}{ Measures } & \multicolumn{2}{|c|}{ M5 } & \multicolumn{2}{|c|}{ M6 } & \multicolumn{2}{|c|}{ M7 } & \multicolumn{2}{|c|}{ M8 } & \multicolumn{2}{|c|}{ M9 } \\
\hline & $\beta$ & SE & $\beta$ & SE & $\beta$ & SE & $\beta$ & SE & $\beta$ & SE \\
\hline $\operatorname{Sex}^{1}$ & .36 & .24 & .35 & .24 & .39 & .24 & .57 & $.26 *$ & .55 & $.26 *$ \\
\hline $\mathrm{MS}^{2}$ & .14 & .25 & .14 & .25 & .19 & .25 & .20 & .26 & .21 & .26 \\
\hline \multicolumn{11}{|l|}{ Education $^{3}$} \\
\hline $\begin{array}{l}\text { Less than } \\
\text { HS } \\
\text { Diploma }\end{array}$ & .23 & .29 & .22 & .29 & .23 & .29 & .34 & .30 & .34 & .30 \\
\hline $\begin{array}{l}\text { GED/HS } \\
\text { Diploma }\end{array}$ & .21 & .29 & .21 & .29 & .17 & .29 & .21 & .30 & .22 & .30 \\
\hline $\begin{array}{l}\text { Number of } \\
\text { Children }\end{array}$ & -.16 & $.05^{*}$ & -.16 & $.05 *$ & -.16 & $.05^{*}$ & -.14 & $.05 *$ & -.15 & $.05 *$ \\
\hline $\begin{array}{l}\text { Lived with } \\
\text { Children } \\
(\text { yes = 1) }\end{array}$ & .68 & $.25^{*}$ & .68 & $.25 *$ & .65 & $.25^{*}$ & .68 & $.25 *$ & .71 & $.25 *$ \\
\hline $\begin{array}{l}\text { Age of Target } \\
\text { Child }\end{array}$ & & & .01 & .04 & .01 & .04 & -.00 & .04 & -.01 & .04 \\
\hline $\begin{array}{l}\text { Substance } \\
\text { Abuse } \\
(\text { yes }=1)\end{array}$ & & & & & -.49 & .43 & -.40 & .44 & -.36 & .44 \\
\hline $\begin{array}{l}\text { Total } \\
\text { Sentence } \\
\text { Length }\end{array}$ & & & & & & & .22 & $.10 *$ & .66 & .42 \\
\hline $\begin{array}{l}\text { Length of Inc. } \\
\text { at Base. }\end{array}$ & & & & & & & & & -.46 & .42 \\
\hline Constant $^{4}$ & .59 & .34 & .54 & .47 & .95 & .59 & .36 & .64 & .14 & .67 \\
\hline
\end{tabular}

$* \mathrm{p}<.05$

${ }^{1}$ Sex: Female $=1$, Male $=0$

${ }^{2} \mathrm{MS}=$ Minority Status. The omitted MS category is Other $=0$.

${ }^{3}$ The omitted Education category is At least some college $=3$.

${ }^{4} \mathrm{M} 1$ and 4 were $\mathrm{p}<.05$. M2 and 3 were not statistically significant. 
Appendix A.7

Logistic Regression of whether all three indirect communications were utilized

\begin{tabular}{|c|c|c|c|c|c|c|c|c|c|c|}
\hline \multirow[b]{2}{*}{ Measures } & \multicolumn{2}{|c|}{ M5 } & \multicolumn{2}{|c|}{ M6 } & \multicolumn{2}{|c|}{ M7 } & \multicolumn{2}{|c|}{ M8 } & \multicolumn{2}{|c|}{ M9 } \\
\hline & $\beta$ & SE & $\beta$ & SE & $\beta$ & SE & $\beta$ & $\mathrm{SE}$ & $\beta$ & $\mathrm{SE}$ \\
\hline $\operatorname{Sex}^{1}$ & .17 & .31 & .19 & .31 & .17 & .32 & .39 & .33 & .29 & .34 \\
\hline $\mathrm{MS}^{2}$ & .04 & .33 & .03 & .33 & .01 & .33 & -.01 & .34 & .02 & .34 \\
\hline \multicolumn{11}{|l|}{ Education $^{3}$} \\
\hline $\begin{array}{l}\text { Less than } \\
\text { HS } \\
\text { Diploma }\end{array}$ & -.05 & .37 & -.03 & .37 & -.03 & .37 & .09 & .38 & .10 & .38 \\
\hline $\begin{array}{l}\text { GED/HS } \\
\text { Diploma }\end{array}$ & .32 & .39 & .33 & .40 & .35 & .40 & .41 & .40 & .44 & .41 \\
\hline $\begin{array}{l}\text { Number of } \\
\text { Children }\end{array}$ & -.17 & $.06 *$ & -.17 & $.06^{*}$ & -.17 & $.06^{*}$ & -.15 & $.06^{*}$ & -.17 & $.06^{*}$ \\
\hline $\begin{array}{l}\text { Lived with } \\
\text { Children } \\
(\text { yes = 1) }\end{array}$ & .55 & .33 & .55 & .33 & .56 & .33 & .59 & .33 & .68 & $.34 *$ \\
\hline $\begin{array}{l}\text { Age of Target } \\
\text { Child }\end{array}$ & & & -.02 & .06 & -.02 & .06 & -.04 & .06 & -.04 & .06 \\
\hline $\begin{array}{l}\text { Substance } \\
\text { Abuse } \\
(\text { yes = 1) }\end{array}$ & & & & & .26 & .51 & .45 & .52 & .61 & .54 \\
\hline $\begin{array}{l}\text { Total } \\
\text { Sentence } \\
\text { Length }\end{array}$ & & & & & & & .34 & $.16^{*}$ & 1.66 & $.59 *$ \\
\hline $\begin{array}{l}\text { Length of Inc. } \\
\text { at Base. }\end{array}$ & & & & & & & & & -1.36 & $.58 *$ \\
\hline Constant $^{4}$ & 1.95 & $.44^{*}$ & 2.11 & $.61^{*}$ & 1.91 & $.73^{*}$ & 1.11 & .79 & .45 & .85 \\
\hline
\end{tabular}

${ }^{*} \mathrm{p}<.05, * * \mathrm{p}<.000$

${ }^{1}$ Sex: Female $=1$, Male $=0$

${ }^{2} \mathrm{MS}=$ Minority Status. The omitted MS category is Other $=0$.

${ }^{3}$ The omitted Education category is At least some college $=3$.

${ }^{4} \mathrm{M} 1-4$ were $\mathrm{p}<.05$ 
Appendix B

Human Subjects Research Review Committee

\section{Portland State}

Post Office Box 751

Portland, Oregon 97207-0751
503-725-4288 tel

503-725-8170 fax

hsrrc@lists.pdx.edu

To: $\quad$ Sarah Lazzari

From: HSSRC

Date: February 13, 2012

Re: HSRRC waived review of your application titled, “The Influence of Parental Gender on the Type of Communication between Incarcerated Parents and Their Children” (HSRRC \#122042)

Even with the exemption above, it was necessary by University policy for you to notify this Committee of the proposed research, and we appreciate your timely attention to this matter. If you make changes in the research protocol, the Committee must be notified in writing, and changes must be approved before being implemented.

If you have questions or concerns, please contact the HSRRC in the Office of Research and Strategic Partnerships (RSP), (503) 725-2243, Market Center Building, $6^{\text {th }}$ floor.

cc: Ann Stephenson

Laura Hickman 